\title{
EL SISTEMA AFRICANO DE DERECHOS HUMANOS Y DE LOS PUEBLOS. PROLEGÓMENOS
}

\author{
Yuria SAAVEDRA ÁlVAREZ*
}

RESUMEN: El sistema africano de derechos humanos y de los pueblos se basa en la Carta Africana de Derechos Humanos y de los Pueblos, un documento único que reúne tanto derechos individuales y colectivos como deberes individuales, entre otras originalidades, y prevé una Comisión Africana como un órgano que ejerce una supervisión continental total. Recientemente, entró en vigor un Protocolo adicional a la Carta que establece una Corte Africana. Sin embargo, a pesar de sus numerosas innovaciones, características y críticas, sobre todo en términos de los derechos reconocidos, sus garantías, instituciones y sus veinte años de funcionamiento, no se ha generado mucho interés en el ámbito académico latinoamericano como en otras regiones del mundo. Este artículo constituye una breve introducción al tema con la intención de establecer un primer fundamento de estudio para aquellos interesados en el derecho internacional de los derechos humanos.

ABSTRACT: The African Human and Peoples' Rights System is mostly based on the African Charter on Human and Peoples' Rights, a unique document that embraces together individual and collective rights and individual duties, among other novelties, and foresees an African Commission as an organ that exercises a complete continental supervision. Recently, an additional Protocol to the Charter establishing an African Court has entered into force. However, despite its many innovations, features and criticism, above all in terms of the rights recognized, its guarantees, institutions and the twenty years system's practice, it has not generated much interest in the Latin-American academic discourse as in other regions of the world. This article constitutes a brief introduction to the topic aimed at establishing a first basis of study for those interested in the international human rights law.

RÉSUMÉ: Le Système africain de protection des Droits de l'Homme et des Peuples est essentiellement basé sur la Charte africaine des Droits de l'Homme et des Peuples, un document unique qui comprend - entre autres nouveautés - à la fois les droits individuels et collectifs et les devoirs individuels, et qui prévoit une Commission africaine comme organe exerçant une surveillance continentale complète. Récemment, un Protocole additionnel à la Charte, créant une Cour africaine, est entré en vigueur. Toutefois, malgré ses nombreuses innovations, caractéristiques et critiques — surtout en ce qui concerne les droits reconnus, leurs garanties, les institutions et la pratique du système sur une période de vingt ans-celui-ci n'a pas suscité autant d'intérêt dans le discours académique latino-américain que dans les autres régions du monde. Cet article constitue une brève introduction à ce sujet, afin d'établir une première base d'étude pour ceux et celles intéressés par le droit international des droits de la personne.

* Maestra en derecho internacional de los derechos humanos por la Universidad de Utrecht, Países Bajos, y profesora en la Facultad de Derecho de la UNAM. 
Taking into consideration the virtues of their historical tradition and the values of African civilization which should inspire and characterize their reflection on the concept of human and peoples' rights.

Preámbulo de la Carta Africana de Derechos Humanos y de los Pueblos.

SUMARIO: I. Introducción. II. La Carta Africana de Derechos Humanos y de los Pueblos. III. La Comisión Africana de Derechos Humanos y de los Pueblos. IV. La Corte Africana de Derechos Humanos y de los Pueblos. V. Conclusiones.

\section{INTRODUCCIÓN}

Tuvieron que pasar casi treinta y tres años desde la adopción de la Declaración Universal de Derechos Humanos, en 1948, para que los Estados africanos decidieran comprometerse regionalmente con la protección de los derechos humanos. El 27 de junio de 1981 la Asamblea de Jefes de Estado y de Gobierno de la entonces Organización de la Unidad Africana ${ }^{1}$ adoptó la Carta Africana de Derechos Humanos y de los Pueblos (en adelante, Carta Africana o Carta), en Nairobi, Kenya. Este tratado es el primer instrumento africano de derechos humanos, resultado del largo proceso de adopción del concepto mismo de "derechos humanos" que los Estados africanos hicieron suyo para alcanzar su independencia, principalmente durante los años sesenta. Difícilmente podría afirmarse que los derechos humanos, como tales, existieron en el África precolonial. Incluso durante la colonización del continente, y aun habiendo sido ya planteados en Europa, los colonizadores se negaron a reconocer estos derechos en su expresión máxima. ${ }^{2}$

Sin embargo, a partir de la segunda mitad del siglo XX fue inevitable que los países africanos — entonces colonias - proclamaran su independencia y soberanía abanderados por el derecho a la autodeterminación,

1 Ahora sustituida por la Unión Africana a partir de la adopción de su Acta Constitutiva el 11 de julio de 2000 en Lomé, Togo, en vigor desde el 26 de mayo de 2001. Este instrumento puede consultarse en African Union, http://www.africa-union.org/root/au/ AboutAU/Constitutive_Act_en.htm (última visita el 21 de febrero de 2007).

2 Lo anterior, quizá también porque esos derechos tampoco eran "universales" en las metrópolis. 
un derecho de los pueblos por excelencia. A partir de ahí, los nuevos Estados africanos se fueron incorporando a la Organización de las Naciones Unidas, y casi movidos por la misma inercia de la reciente emancipación, fueron adhiriéndose a los primeros tratados internacionales de derechos humanos. Sin embargo, la propia tendencia hacia la regionalización, y en gran medida la presión ejercida por las Naciones Unidas, hicieron que los Estados africanos aceptaran crear un sistema propio de derechos humanos. Entre las ventajas que encontraron fue precisamente la introducción de cierto relativismo cultural en la Carta Africana. En su preámbulo, este instrumento se refiere a la tradición y valores de la civilización africana como parámetros para conceptualizar a los derechos humanos y de los pueblos. ${ }^{3}$

En este sentido, aunque la Carta reconoce también la universalidad de los derechos humanos ${ }^{4}$ al mismo tiempo intenta reafirmar y preservar aquellos baluartes culturales africanos que parecen estar "en riesgo" frente a la civilización occidental. Son precisamente estas características lasque definen y moldean al sistema africano de derechos humanos y de los pueblos (en adelante, "sistema africano"). A continuación nos referiremos a éste brevemente, haciendo énfasis sólo en los aspectos principales tanto sustantivos como adjetivos. Para ello, abarcaremos solamente a los órganos que tienen un mandato específico sobre derechos humanos, es decir, la comisión y la corte africanas de derechos humanos y de los pueblos. ${ }^{5}$ Evidentemente, se trata de un tema muy vasto y complejo, por lo

3 Párrafo 50.

4 Cfr., por ejemplo, el párrafo 7o. del Preámbulo.

5 El sistema africano se integra a su vez por un Comité de los Derechos y el Bienestar del Niño, sin embargo, como se trata de un órgano con una competencia muy específica, y dado que se conoce muy poco sobre su labor, no está incluido en el presente trabajo. Este Comité fue establecido por la Carta Africana sobre Derechos y el Bienestar del Niño adoptada por la Asamblea de Jefes de Estado y de Gobierno de la extinta Organización de la Unidad Africana en Addis Abeba, Etiopía, en julio de 1990 y en vigor desde el 29 de noviembre de 1999. Puede consultarse en African Union, http://www.afri ca-union.org/root/au/Documents/Treaties/Text/A.\%20C.\%20ON\%20THE\%20RIGHT\%2 $0 A N D \% 20$ WELF\%20OF\%20CHILD.pdf (última visita el 21 de febrero de 2007). Además, el 25 de noviembre de 2005 entró en vigor el Protocolo a la Carta Africana de Derechos Humanos y de los Pueblos sobre los Derechos de las Mujeres en África. Éste puede consultarse en African Union, http://www.africa-union.org/root/au/Documents/Trea ties/ Text/Protocol\%20on\%20the\%20Rights\%20of\%20Women.pdf (última visita el 13 de marzo de 2007). 
que este espacio resulta insuficiente para su análisis a detalle. ${ }^{6}$ No obstante, nuestro propósito es proporcionar un breve esbozo que permita empezar a elaborar estudios sobre este sistema de derechos humanos que resulta desconocido para la gran mayoría de académicos y practicantes, inclusive para estudiosos del derecho internacional, particularmente en México.

\section{LA CARTA AFRICANA DE DERECHOS HuMANOS Y DE LOS PUEBLOS}

La Carta Africana de Derechos Humanos y de los Pueblos es el primer intento significativo en África para tomar "los derechos en serio".? Este instrumento fue redactado durante un momento de intensa frustración entre los africanos, provocada en gran parte por el desinterés de la Organización de la Unidad Africana en la efectiva protección de los derechos humanos. ${ }^{8}$ Aunque la Carta es similar a otros tratados regionales de derechos humanos, su historia no puede ser trazada en el mismo contexto que el de aquéllos. La situación especial de dependencia económica y política, y los problemas endémicos al subdesarrollo de ese continente se refleja claramente en el tipo de derechos garantizados y en los mecanismos de protección previstos para ese efecto. En términos generales, la Carta Africana combina valores y necesidades específicos de los pueblos africanos con estándares "universales", logrando exaltar y marcar las diferencias esenciales del sistema. La Carta es muy innovadora y se separa de los instrumentos tradicionales de derechos humanos que dan preemi-

6 Sin embargo, para mayor abundamiento sobre el sistema africano de derechos humanos y de los pueblos, pueden consultarse: Saavedra Álvarez, Yuria, La Comisión Africana de Derechos Humanos y de los Pueblos: Organización y Funcionamiento, UNAM, Facultad de Derecho, 2004, tesis de licenciatura, 365 pp., e id., Execution of Judgements of the African Court of Human and Peoples' Rights, Utrecht University, Faculty of Law, 2005, tesis de maestría, 112 pp.

7 La Carta Africana fue "the first serious and potentially significant attempt by African leaders towards 'taking rights seriously", Udombana, Nsongurua J., "Can the Leopard change its spots? The African Union Treaty and Human Rights", American University International Law Review, Washington, vol. 17, núm. 6, 2002, pp. 1206 y 1207.

8 Sobre los antecedentes de la Carta Africana, $c f r$. Don Nanjira, Daniel D. C., "The Protection of Human Rights in Africa: The African Charter on Human and Peoples' Rights", en Symonides, Janusz (comp.), Human Rights: International Protection, Monitoring Enforcement, Aldershot, UNESCO, 2002, pp. 217-219. 
nencia a los derechos clásicos, es decir, los individuales o liberales, para incluir en un mismo plano a los derechos colectivos —en su sentido más amplio - Como resultado, la Carta Africana contempla no sólo derechos de las llamadas primera y segunda generaciones - algo por sí mismo único en los diversos sistemas internacionales de derechos humanossino además derechos de tercera generación o de los pueblos. ${ }^{9}$ La idea principal que se refleja es que los derechos individuales no son la única piedra angular, y por lo tanto, en la Carta Africana se procura integrar a las tradiciones africanas - preponderantemente con un matiz colectivo o comunitario antes que individual - a la herencia común de los derechos humanos.

A diferencia de lo que podría adelantarse, el sistema africano de derechos humanos, específicamente la estructura con base en la Carta Africana, goza de un consenso absoluto. Los cincuenta y tres Estados miembros de la Unión Africana son partes de la Carta, lo cual significa que todos ellos se encuentran obligados a garantizar los derechos ahí contemplados, y que están sometidos a los procedimientos de supervisión y control de la Comisión Africana de Derechos Humanos y de los Pueblos. ${ }^{10}$ Sin embargo, reconocemos que ello por sí mismo no garantiza la efectividad y aceptación incondicional del sistema, pero al menos demuestra cierta voluntad e interés de los Estados africanos hacia el tema.

\section{Principales características}

La Carta Africana se encuentra muy influenciada por sus instrumentos regionales predecesores, es decir, el Convenio para la Protección de los Derechos Humanos y las Libertades Fundamentales de 1950 (Convención Europea) y la Convención Americana sobre Derechos Humanos de 1969 (Convención Americana). Sin embargo, la Carta Africana en

9 Sobre los derechos de los pueblos en la Carta Africana, $c f r$. Kiwanuka, Richard, "The Meaning of People in the African Charter on Human and Peoples' Rights", American Journal on International and Comparative Law, Washington, vol. 82, 1991, p. 307.

10 En el ámbito del sistema europeo de derechos humanos se establece como un requisito inexcusable para la membresía del Consejo de Europa, órgano dentro del cual se enmarca este sistema, la aceptación obligatoria del Convenio para la Protección de los Derechos Humanos y las Libertades Fundamentales, mientras que este requisito no existe en el marco de la Unión Africana, por lo que es todavía más destacable la amplia aceptación de la Carta por parte de los estados africanos. 
más ambiciosa en varios aspectos. ${ }^{11}$ Los derechos civiles y políticos son prácticamente los mismos, sin embargo, en contraste, los derechos económicos, sociales, culturales y de los pueblos se encuentran garantizados a la par que aquéllos, es decir, todos estos derechos se encuentran en un mismo documento y no en diferentes instrumentos como sucede en los sistemas europeo e interamericano. ${ }^{12}$ Ya el preámbulo de la Carta señala que "los derechos civiles y políticos no pueden disociarse de los derechos económicos, sociales y culturales en su concepción y universalidad, y que la satisfacción de los derechos económicos, sociales y culturales es una garantía para el disfrute de los derechos civiles y políticos". ${ }^{13}$

La Carta también establece sus propios mecanismos de implementación y supervisión de derechos, aunque con notas sutilmente distintivas a los sistemas europeo e interamericano. Existen mecanismos de comunicaciones individuales e interestatales, es decir, la Comisión Africana de Derechos Humanos y de los Pueblos (en adelante, Comisión), órgano creado en virtud de la propia Carta, está facultada para recibir comunicaciones y quejas presentadas entre Estados y por individuos contra éstos, en las que se aleguen violaciones a los derechos garantizados por la Carta. Si así lo estima necesario, al final del procedimiento respectivo —al

11 Incluso la propia Comisión Africana de Derechos Humanos y de los Pueblos así lo ha reconocido; al respecto, cfr. "Presentation of the 3rd Activity Report", Third Activity Report of the African Commission on Human and Peoples' Rights 1989-2000, anexo VII, párrafo 6.

12 En el marco del Consejo de Europa, los derechos civiles y políticos se encuentran protegidos por la Convención Europea, mientras que la Carta Social Europea, como su denominación lo indica, garantiza derechos sociales. En el sistema interamericano, los derechos civiles y políticos se encuentran reconocidos en la Convención Americana; este mismo tratado, en un único artículo, hace una referencia indirecta a los derechos económicos, sociales y culturales (DESC) que consiste en la adopción de las medidas que sus Estados partes deben adoptar para garantizar estos derechos — artículo 26- Los DESC se encuentran garantizados por el Protocolo Adicional a la Convención Americana sobre Derechos Humanos en Materia de Derechos Económicos, Sociales y Culturales, conocido como "Protocolo de San Salvador". En el ámbito de las Naciones Unidas, los derechos civiles y políticos se encuentran en el Pacto Internacional de Derechos Civiles y Políticos, mientras que los DESC están garantizados por el Pacto Internacional de Derechos Económicos, Sociales y Culturales, ambos de 1966.

13 "That civil and political rights cannot be dissociated from economic, social and cultural rights in their conception as well as universality and that the satisfaction of economic, social and cultural rights is a guarantee for the enjoyment of civil and political rights", párrafo 7o. 
cual nos referiremos más adelante- la Comisión puede elaborar las recomendaciones pertinentes y señalar al Estado de que se trate las reparaciones respectivas para remediar las violaciones, ${ }^{14}$ las cuales se hacen del conocimiento de la Asamblea General de Jefes de Estado y de Gobierno de la Unión Africana (Asamblea General o Asamblea) a través de su informe anual. Sin embargo, tanto el mecanismo de comunicaciones individuales como el de las interestatales pueden ser iniciados cualquiera que sea el derecho que se alegue, es decir, individual o colectivo; de primera, segunda o tercera generaciones. Esta característica convirtió a la Comisión Africana en el primer órgano internacional de su tipo que puede conocer de casos específicos por violaciones a derechos económicos, sociales, culturales y de los pueblos, hecho que no tiene parangón en ningún otro sistema internacional o regional de derechos humanos. ${ }^{15}$ La Carta también contempla un mecanismo de informes periódicos que deben presentar los Estados cada determinado tiempo sobre la situación general en la que se encuentran los derechos humanos en su jurisdicción. Aunque este método de supervisión ya existe en otros sistemas, en contraste, en el ámbito africano los Estados deben informar sobre cualquier tipo de derecho y no solamente sobre aquellos de tipo económico, social y cultural. Ello permite, precisamente, lograr un "diálogo constructivo" entre la Comisión Africana y los Estados, y resulta mucho más atractivo que las comunicaciones individuales e interestatales en sistemas jurídicos que no son necesariamente, o que lo son en menor medida, de tipo contradictorio como en los sistemas occidentales.

Por otro lado, la Carta Africana tiene dos particularidades. Una de ellas, ya mencionada, es la relativa a la inclusión en un solo instrumento de derechos tanto individuales como colectivos. Aparentemente, los últimos fueron previstos debido a la presión ejercida por los entonces países socialistas como Etiopía y Mozambique. La importancia de la referencia a ambas categorías de derechos es una señal de que la violación a cualquier tipo de derecho, incluso si son colectivos, conlleva necesariamente consecuencias jurídicas que obligan a su reparación; en otras palabras,

14 Al respecto, puede consultarse ampliamente Umozurike, Oji, "The Complaint Procedures of the African Commission on Human and Peoples' Rights", en Alfredsson, Gudmundur et al. (comps.), International Human Rights Monitoring Mechanisms, La Haya, Martinus Nijhoff Publishers, 2001, p. 711.

15 El segundo órgano es la Corte Africana de Derechos Humanos y de los Pueblos, a la cual nos referiremos más adelante. 
no existe derecho alguno que no pueda hacerse efectivo o que no esté garantizado. ${ }^{16} \mathrm{Sin}$ embargo, la gran discusión es, precisamente, cómo lograr la garantía efectiva de derechos considerados como de "desarrollo progresivo" mediante la denuncia específica contra Estados. En este sentido, la experiencia de la Comisión Africana es muy interesante. Este órgano en varias ocasiones se ha pronunciado sobre derechos colectivos a través del sistema de peticiones individuales. Independientemente del fondo de sus pronunciamientos, la Comisión ha señalado que los Estados tienen obligaciones de garantía inmediata respecto a este tipo de derechos. ${ }^{17}$

La proclamación tanto de derechos individuales como colectivos refleja valores y la idea de una "civilización africana". Uno de los argumentos a favor de los derechos de los pueblos es que éstos complementan a los derechos individuales más que excluirlos o limitar su ejercicio, pues en las condiciones actuales de ese continente "el total disfrute de los derechos humanos individuales está inseparablemente condicionado por el respecto y reconocimiento de los derechos de los pueblos a los que pertenecen". ${ }^{18}$ Es en este sentido que la Carta Africana también represen-

16 Cfr. Odinkalu, Chidi Anselm, "Implementing Economic, Social and Cultural Rights", en Evans, Malcolm y Murray, Rachel (comps.), The African Charter on Human and Peoples' Rights: The System in Practice 1986-2000, Cambridge, Cambridge University Press, 2002, pp. 178-218. Este tema es muy pertinente en el marco del proyecto del protocolo facultativo al Pacto Internacional de Derechos Económicos, Sociales y Culturales, en el cual se propone crear un sistema de peticiones individuales para demandar la violación a DESC. Como es bien conocido, con base en este instrumento los estados solamente se encuentran obligados a presentar informes periódicos sobre la implementación de estos derechos.

17 Hasta ahora, el caso más emblemático es uno relativo a DESC y derechos de los pueblos, entre otros, específicamente sobre el derecho a la salud física en relación con el derecho a un medio ambiente adecuado. La Comisión analizó los efectos perjudiciales que tienen las actividades de una empresa petrolera en los habitantes de una comunidad, pero considerados tanto individual como grupalmente. Cfr. Communication 155/96 The Social and Economic Rights Action Center and the Center for Economic and Social Rights $v$. Nigeria. En adelante, todas las comunicaciones a que se haga referencia han sido tramitadas ante la Comisión Africana de Derechos Humanos y de los Pueblos, a menos que se indique otra cosa.

18 "The full enjoyment of individual human rights is inseparable conditioned by the respect and recognition of the rights of the people to which they belong", Boven, Theo van, "The Relations Between Peoples' Rights and Human Rights in the African Charter", Human Rights Law Journal, vol. 7, 1986, p. 192. 
ta un documento emblemático al incluir la noción de "pueblos" en un instrumento internacional plenamente obligatorio. A este término se hace mención en ocho de diez párrafos en su preámbulo, a la vez que la Carta incluye en su catálogo de derechos también aquéllos de los "pueblos". Incluso, hay quienes consideran que la única innovación de la Carta Africana es el hecho de haber logrado un lazo entre los derechos humanos y los derechos de los pueblos — aparentemente basados en características esenciales de las sociedades africanas, como la "solidaridad" en el grupo- en una especie de simbiosis entre el individuo, la comunidad y la sociedad. ${ }^{19}$ Aunque el reconocimiento de los derechos de los pueblos se logró debido a la insistencia de países socialistas, es importante hacer notar que en la Carta no puede encontrarse un concepto totalmente socialista de estos derechos. ${ }^{20}$ Por otro lado, y quizá ella sea una de las principales críticas, en la Carta Africana no puede encontrarse un concepto único de "pueblo". ${ }^{21}$ De hecho, se considera que los redactores de la Carta ni siquiera intentaron definir el concepto de "pueblos", que deliberadamente no lo definieron o que simplemente lo dejaron lo suficientemente amplio para que pudiera ser interpretado de acuerdo a su "significado funcional", ya que este término puede hacer alusión a diferentes conceptos. ${ }^{22}$ Tampoco la Comisión Africana se ha propuesto determinar con exactitud el término. En varios casos, ésta ha considerado que "pueblo"

19 Cfr. Mbaya, Etienne Richard, "Relations between Individual and Collective Rights", Law and State, vol. 46, 1992, p. 13. Otros instrumentos internacionales como el Pacto Internacional de Derechos Civiles y Políticos y el Pacto Internacional de Derechos Económicos, Sociales y Culturales ya hacían referencia al derecho a la autodeterminación. Sin embargo, la Carta Africana es el primer instrumento obligatorio en incluir un catálogo extenso de derechos de los pueblos.

20 Al respecto, puede consultarse Benedek, Wolfgang, "The Judiciary and Human Rights in Africa. The Banjul Seminar and the Training Workshop for a Core of Human Rights Advocates of November 1989”, Human Rights Law Journal, vol. 11, núm. $1-2,1990$, p. 250.

21 La Carta que "la realidad y el respeto de los derechos de los pueblos necesariamente deben garantizar los derechos humanos" (resaltado del autor). Cfr. el Preámbulo, párrafos 4o. y 50 .

22 Cfr. Bello, Emmanuel G., "The African Charter on Human and Peoples' Rights. A Legal Analysis", Recueil des Cours. Collected Courses of the Hague Academy of International Law, Dordrecht, Martinus Nijhoff Publishers, 1985, vol. 194, p. 32; Mbaya, Etienne Richard, "Relations between Individual...", cit., nota 19, p. 13; y Benedek, Wolfgang, "The Judiciary and Human Rights...", cit., nota 20, p. 250. 
es la población de un Estado, ${ }^{23}$ aunque "pueblo" no es el Estado en sí mismo; ${ }^{24}$ tampoco ha señalado expresamente que el vocablo se refiera a una minoría o grupo étnico, ${ }^{25}$ por ejemplo, sutilmente ha mencionado que "pueblo" puede ser una entidad distinta a la población total del Estado. ${ }^{26}$ La Comisión también ha interpretado indirectamente el concepto de pueblo como un grupo identificable por sus ancestros, origen étnico, idioma o hábitos culturales comunes. ${ }^{27}$ En otro caso, aun cuando no lo define, se refiere al "pueblo" de Ogoni, el cual es una comunidad de personas al interior de Nigeria. ${ }^{28}$ Por lo tanto, la propia Comisión ha reconocido que existe controversia en la definición de "pueblos". ${ }^{29}$ Piénsese, sólo por mencionar, en el derecho a la autodeterminación de los pueblos y en lo complicado y delicado que puede llegar a ser el determinar un concepto único de "pueblo".

Por otro lado, la Carta no solamente reconoce derechos sino que también establece un catálogo de deberes, hecho que es muy novedoso en un tratado de derechos humanos. ${ }^{30}$ Para quien considere que los derechos no tendrían mucho sentido sin sus correlativos deberes, no resulta extraña su

23 Se refiere al "pueblo" de Sudáfrica, $c f r$. Third Activity Report of the African Commission on Human and Peoples' Rights 1989-1990, párrafo 14.

24 Menciona al "pueblo" de Ruanda, cfr. "Press Release", Seventh Annual Activity Report of the African Commission on Human and Peoples' Rights 1993-1994, anexo XIII, 3o. y último párrafo.

25 Cfr. Murray, Rachel, The African Commission on Human and Peoples' Rights and International Law, Oxford, Hart Publishing, 2000, p. 105; esta autora cita como ejemplo lo señalado por la Comisión Africana en Communications 27/89, 46/91, 49/91, 99/93 Organisation Mondiale Contre La Torture, Association Internationale des Juristes Democrates, Commission Internationale des Juristes, Union Interafricaine des Droits de l'Homme $v$. Rwanda.

26 Cfr. "Resolution on Zaire", Tenth Annual Activity Report of the African Commission on Human and Peoples' Rights 1993-1994, anexo XI, párrafo 20.

27 Cfr. Communication 211/98 Legal Resources Foundation v. Zambia, párrafo 73. Cfr. también "Resolution on the Rights of Indigenous People/Communities in Africa", African Commission on Human and Peoples' Rights, http://www.achpr.org/Recommen dations_Resolutions-_ACHPR_88-02.pdf, pp. 67 y 68, última visita el 12 de abril de 2005.

28 Cfr. Communication 155/96..., cit., nota 17, párrafo 62.

29 Cfr. Communication 75/92 Katangese Peoples' Congress $v$. Zaire, párrafo 3o.

30 Para un desarrollo más amplio sobre el significado de la inclusión de "deberes" en la Carta Africana, puede consultarse Mutua, Bakau Wa, "The Banjul Charter and the African Cultural Fingerprint: An Evaluation of the Language of Duties", Virginia Journal of International Law, Washington, vol. 35, 1995, pp. 340 y 341. 
inclusión en un sólo documento. ${ }^{31}$ No obstante, la Carta Africana es el primer instrumento regional obligatorio - por tratarse de un tratado internacional y no de una mera declaración - en incluir un catálogo de deberes en términos más precisos y extensos, reafirmando la premisa de que los derechos y los deberes existen concomitantemente. ${ }^{32}$ Esto se explica si se tiene presente la historia de los derechos humanos en el África precolonial, durante la cual la dualidad derechos-deberes se afianzó en las prácticas africanas. ${ }^{33}$ En este sentido, la Carta impone a los individuos deberes hacia la familia, la sociedad, el Estado, la comunidad internacional y otras comunidades legalmente reconocidas. ${ }^{34}$ Pero, además, con la inclusión de derechos y deberes, la Carta se aparta y evoluciona respecto a otros tratados internacionales en su concepción común del efecto vertical de las obligaciones de los Estados hacia los individuos para introducir la noción del efecto horizontal de las obligaciones, es decir, la de los individuos entre sí. ${ }^{35}$ Sobre este tema, el principal problema es cómo hacer efectivo el cumplimiento de los deberes individuales a través de mecanismos que han sido diseñados para demandar derechos a los Estados. Como ya ha sido establecido en otros foros internacionales, y aunque no sea una única solución, la Comisión Africana ha señalado que los Estados pueden ser responsables internacionalmente si no toman las

31 El primer instrumento internacional que estableció deberes fue la Declaración Universal de Derechos Humanos, en su artículo 29, párrafo 10. Sin embargo, ésta se refiere solamente a los deberes hacia la "comunidad". En el sistema interamericano, la Declaración Americana de los Derechos y Deberes del Hombre comprende una lista extensa de deberes individuales en sus artículos XXIX a XXXVIII, no obstante, se trata de una resolución de la Asamblea General de la Organización de Estados Americanos y no de un tratado internacional conforme al artículo 2o., párrafo 1o., inciso a), de la Convención de Viena sobre el Derecho de los Tratados de 1969; la Convención Americana sobre Derechos Humanos vagamente establece en su artículo 32, párrafo 1o., que "Toda persona tiene deberes para con la familia, la comunidad y la humanidad", sin señalar cuáles son esos deberes en lo particular.

$32 C f r$. Viljoen, Frans, "Africa's contribution to the development of international human rights and humanitarian law", African Human Rights Law Journal, Sudáfrica, vol. 1, núm. 1, 2001, p. 21.

33 Tradicionalmente, los derechos eran inseparables de los deberes lo cual conllevaba al reconocimiento tanto del individuo como del grupo. Cfr. Bello, Emmanuel G., "The African Charter...", cit., nota 22, p. 33.

34 Artículos 27 a 29.

35 Cfr. Murray, Rachel, The African Commission on Human and Peoples' Rights and International Law, Oxford, Hart Publishing, 2000, p. 40. 
medidas apropiadas para proteger a los individuos de actos cometidos por otros individuos que incumplan sus deberes $-\mathrm{y}$, por lo tanto, violen al mismo tiempo sus derechos humanos-. ${ }^{36}$

Sin embargo, particularmente desde una visión occidental de los derechos, se ha argumentado que la imposición de deberes también podría servir a los gobiernos para limitar indebidamente el ejercicio de los derechos. ${ }^{37}$ Consideramos que esta afirmación socava en cierta medida la noción africana de los derechos humanos, es decir, es necesario tomar en cuenta las culturas y filosofías africanas para comprender el carácter único de la Carta Africana y de su referencia tanto a derechos como a deberes. ${ }^{38}$ No obstante, reconocemos que el respeto de los derechos no está condicionado por el cumplimiento de los deberes, ya que en ambas situaciones, por lo menos en el contexto internacional, las obligaciones directas siempre recaen en los Estados. En otras palabras, los Estados deben reconocer no solamente los derechos sino también los deberes, y por lo tanto, deben adoptar medidas tanto para el respeto de unos como para el cumplimiento de los otros.

Asimismo, la Carta Africana también tiene un rasgo distintivo al no establecer cláusulas generales de suspensión de derechos. ${ }^{39}$ En su lugar, la mayoría de los derechos civiles y políticos están sujetos en lo particular a diversas condiciones que limitan su ejercicio bajo determinadas circunstancias. ${ }^{40}$ Debe resaltarse que los derechos económicos, sociales, culturales y de los pueblos no se encuentran sujetos a cláusulas limitativas. Incluso, la Comisión Africana ha señalado que estos derechos no pueden suspenderse ni siquiera en Estados de emergencia o en circunstancias especiales, ${ }^{41}$ precisamente porque el hecho de que la Carta no

36 Cfr. Communication 74/92, Commission Nationale des Droits de l'Homme et des Libertes $v$. Chad, párrafo 18, y Communication 155/96..., cit., nota 17, párrafo 57.

37 Cfr. Bello, Emmanuel, op. cit., nota 22, pp. 178 y 179.

38 Cfr. Ankumah, Evelyn, The African Commission on Human and Peoples' Rights. Practice and Procedures, La Haya, Martinus Nijhoff Publishers, 1996, p. 159. En el África precolonial los deberes de los individuos hacia la comunidad tenían un significado muy relevante pues las personas eran concebidas solamente como parte de un grupo. Esta noción parece ser una de las herencias culturales en la Carta Africana.

39 Sobre el tema, cfr. Rembe, N. S., The System of Protection of Human Rights under the African Charter on Human and Peoples' Rights: Problems and Prospects, Lesotho, Institute of Southern African Studies, 1991, pp. 18-20.

40 Son las denominadas "clawback clauses" o cláusulas de freno o limitativas.

41 Cfr. Communication 74/92..., cit., nota 36, párrafo 21. 
contenga cláusulas de suspensión de derechos puede ser vista como una expresión del principio de que la restricción de los derechos humanos no es una solución a las dificultades nacionales "pues el ejercicio legítimo de los derechos humanos no plantea peligros a un Estado democrático gobernado por un Estado de derecho". ${ }^{42}$ Sin embargo, esta apreciación puede resultar inadecuada en situaciones graves de peligro o de emergencia nacional, cuando los Estados, como lo han hecho en numerosas ocasiones los africanos, suspenden temporalmente ciertos derechos para poder hacer frente a tales circunstancias. ${ }^{43}$ Por ello, las cláusulas de suspensión no deben ser vistas solamente en su aspecto negativo -que es la restricción en sí-. Estas cláusulas desempeñan una doble función, es decir, si bien es cierto que obstruyen el ejercicio de los derechos, también establecen las condiciones precisas bajo las cuales los Estados pueden llegar a limitar los derechos ${ }^{44}$ dando mayor certeza jurídica a sus titulares.

\section{LA COMISIÓN AFRICANA DE DERECHOS HUMANOS Y DE LOS PUEBLOS}

La Comisión Africana de Derechos Humanos y de los Pueblos es el principal órgano de promoción y protección de los derechos humanos en el continente africano. Debe resaltarse que se trata del único órgano contemplado por la Carta para llevar a cabo esas funciones. ${ }^{45}$ Formalmente fue establecida el 21 de octubre de 1986, fecha en que entró en vigor la Carta, aunque inició sus actividades en 1987, cuando celebró su primera sesión ordinaria en Addis Abeba, Etiopía. Su sede se encuentra en Banjul, Gambia. Se compone de once miembros, actualmente nacionales de

42 Communications 48/90, 50/91, 52/91 and 89/93, Amnesty International, Comité Loosli Bachelard, Lawyer's Committee for Human Rights, Association of Members of the Episcopal Conference of East Africa $v$. Sudan, párrafo 79.

43 Así, por ejemplo, la Convención Americana sobre Derechos Humanos autoriza a los Estados a que en situaciones de peligro público, de guerra o de otra emergencia que amenace la independencia o seguridad del Estado pueda suspender parcial y temporalmente ciertos derechos garantizados por este tratado; $c f r$. el artículo 27.

44 Cfr. Heyns, Christof, "The African regional human rights system: In need of reform?", African Human Rights Law Journal, Sudáfrica, vol. 1, núm. 2, 2001, p. 160.

45 La Corte Africana de Derechos Humanos y de los Pueblos fue creada mediante otro tratado internacional. 
Nigeria, Ruanda, Mali, Mozambique, Mauricio, Botswana, Tanzania, Benin, Gambia, Zambia y Sudáfrica. ${ }^{46}$ Los comisionados realizan sus funciones por un periodo de seis años al término de los cuales pueden ser reelectos. ${ }^{47}$ Los candidatos son propuestos por los Estados partes de la Carta y elegidos por la Asamblea General de la Unión Africana. Al frente de la Comisión se encuentran un presidente y un vicepresidente elegidos por los comisionados de entre sus miembros por un periodo de dos años que puede ser renovado sucesivamente. ${ }^{48}$

El artículo 45 de la Carta Africana otorga un mandato muy amplio a la Comisión. Pueden distinguirse cuatro funciones principales: de promoción, de protección, de interpretación y "otras" que le encomiende la Asamblea General. ${ }^{49}$ A continuación nos referiremos a los aspectos más relevantes de cada una de ellas.

\section{Funciones de promoción}

Esta parte de su mandato se encuentra señalada en detalle en el párrafo 1o. del artículo 45 de la Carta Africana. Estas funciones incluyen actividades comunes como recolectar documentos; llevar a cabo estudios e investigaciones sobre los problemas en materia de derechos humanos en el continente africano; organizar conferencias, seminarios y simpo-

46 Conforme a la información publicada en el sitio oficial de la Comisión Africana, actualizada a abril de 2007, cfr. http://www.achpr.org/english/other/achpr_Commissio ner\%27s-eng.pdf (última visita el 22 de mayo de 2007) conjuntamente con Press Release núm. 50/2007, "The five new members of the African Comisión on Human and Peoples' Rights have been elected", 29 de junio de 2007, African Union, http://www.afri ca-union.org/root/au/Conferences/2007/june/summit/Press/ELECTION_CADHP.doc (última visita el 14 de julio de 2007).

47 Artículos 31, párrafo 10., y 36 de la Carta Africana. Es importante hacer notar que este instrumento no específica el número de veces que pueden ser reelegidos los comisionados. Compárese, por ejemplo, con el artículo 37 de la Convención Americana, el cual expresamente señala que los comisionados podrán ser reelectos por una sola vez.

48 Artículo 42 de la Carta Africana. De igual manera, este instrumento no específica el número de veces que pueden ser reelegidos estos funcionarios. Al respecto, el artículo 8o. del Reglamento de la Comisión Interamericana señala que su presidente y vicepresidente podrán ser reelectos sólo por una vez en cada periodo de cuatro años.

49 El artículo 45, párrafo 3o., de la Carta se refiere todavía a la Asamblea de Jefes de Estado y de Gobierno de la Organización de la Unidad Africana. No obstante, cualquier referencia a esta organización debe ser entendida como a la Unión Africana; ya señalamos que este órgano sustituyó desde 2001 a la Organización de la Unidad Africana. 
sios; diseminar información; y estimular a las instituciones locales y nacionales de derechos humanos. La Comisión también está facultada para formular principios y reglas que tengan como objetivo la resolución de problemáticas relativas a la situación de los derechos humanos y de los pueblos en África, sobre los cuales los Estados puedan elaborar e implementar su legislación, y cooperar con otras instituciones u organismos internacionales en la materia.

La promoción quizá no sea tan controversial en tanto que las acciones que lleva a cabo la Comisión no necesariamente ponen al descubierto o cuestionan la actitud de los Estados respecto a la situación de los derechos humanos en sus territorios. No obstante, las actividades promocionales han tenido un impacto importante en el continente africano, llegando, incluso, a constituirse como prioridades. Precisamente, el propósito fundamental de esta faceta es concientizar a la sociedad africana como un esfuerzo para afianzar la protección de los derechos humanos y de los pueblos.

Durante el tiempo en que la Comisión Africana no celebra sesiones, sus comisionados visitan organizaciones de derechos humanos, universidades y otras instituciones, y ofrecen conferencias acerca de la Carta Africana, temas de derechos humanos y sobre el trabajo de la propia Comisión. Posteriormente, en cada periodo de sesiones los comisionados presentan un informe sobre las actividades promocionales que hubieren realizado. ${ }^{50}$ Además, como una manera de involucrar a los Estados africanos en la promoción de los derechos humanos, la Comisión proclamó el 21 de octubre como el "Día de los Derechos Humanos en África", y realizó un llamado a los Estados partes para que celebraran esta fecha, en la cual, además, se conmemora la entrada en vigor de la Carta Africana. ${ }^{51}$ Otras acciones que pueden considerarse como un esfuerzo de la Comisión para promocionar los derechos humanos y de los pueblos es la práctica de celebrar sus sesiones tanto ordinarias como extraordinarias en diferentes países del continente africano. ${ }^{52}$

50 Artículo 87, párrafo 3o., del Reglamento de la Comisión.

51 Cfr. "Resolution on the Celebration of an African Day of Human Rights", African Commission on Human and Peoples' Rights, http://www.achpr.org/Recommendations_ Resolutions-_ACHPR_88-02.pdf, p. 11 (última visita el 10 de abril de 2003).

52 Cfr. Murray, Rachel, The African Commission on Human..., cit., nota 35, p. 15. 
Por otro lado, la jurisprudencia de la Comisión Africana también forma parte del derecho internacional y, como tal, contribuye al establecimiento de los estándares sobre derechos humanos; en este sentido, a través de sus decisiones, la Comisión también realiza funciones de promoción, ${ }^{53}$ aunque el defecto más importante en este sentido lo constituye la falta de información disponible al respecto. ${ }^{54}$

Sin embargo, las visitas de promoción tienden a enfocarse a zonas urbanas e instituciones de un relativo alto nivel intelectual cuando precisamente la educación acerca de los derechos humanos se necesita sobre todo en zonas rurales, donde la tasa poblacional es mayor y el índice de educación suele ser menor. Por otro lado, es complicado que la Comisión lleve a cabo sus actividades de promoción en áreas rurales sin que tome en cuenta el idioma o dialectos particulares. Precisamente por ello, resulta valioso el trabajo que han desarrollado las organizaciones no gubernamentales $(\mathrm{ONG})$ como complemento a la labor promocional de la Comisión. ${ }^{55}$ Sin embargo, por otro lado, es por la falta tanto de recursos humanos como materiales que la Comisión ha tenido que alentar el involucramiento de las ONG para llevar a cabo este tipo de actividades, lo cual ha dado lugar a que sea criticada por su aparente incapacidad para desarrollar por sí misma las funciones. ${ }^{56}$ No obstante, no debe dejarse de reconocer el papel que desempeñan las $\mathrm{ONG}$ en la promoción de los derechos humanos. Comúnmente son éstas las que se encuentran en contacto directo con la población, de tal manera que identifican con mayor facilidad los temas prioritarios que deben ser abordados por la Comisión. A manera de ejemplo, varios de los seminarios son organizados con ONG y éstas preferentemente escogen los contenidos que necesitan ser desarrollados con mayor urgencia. ${ }^{57}$ Cabe mencionar que, incluso, muchas veces

53 Cfr. Odinkalu, Chidi Anselm y Christensen, Camilla, "The African Commission on Human and Peoples' Rights: The Development of its Non-State Communication Procedures", Human Rights Quarterly, Washington, vol. 20, núm. 2, mayo 1998, p. 242.

54 Cfr. Benedek, Wolfgang, "The African Charter on Human and Peoples' Rights: How to Make it More Effective", Netherlands Quarterly on Human Rights, Países Bajos, vol. 11, núm. 1, 1993, p. 29.

55 Cfr. Ankumah, Evelyn, The African Commission on Human..., cit., nota 38, pp. 21 y 22.

56 Cfr. Motala, Ahmed, "Non-governmental organisations in the African system", en Evans, Malcolm y Murray, Rachel, op. cit., nota 16, p. 264.

57 Principalmente, la colaboración ha consistido en ayuda financiera; entre otras, las organizaciones que han participado son: International Centre for Human Rights and De- 
son las ONG y no la Comisión las que elaboran y distribuyen los informes sobre estas actividades. ${ }^{58}$ Las ONG realizan labores importantes de promoción de los derechos humanos, complementando las tareas de la Comisión a través de la difusión de la Carta Africana e informando acerca de los derechos humanos. ${ }^{59}$

\section{Funciones de protección}

Los artículos 46 a 59 de la Carta, así como los artículos 88 a 120 del Reglamento de la Comisión ${ }^{60}$ establecen los procedimientos para el trámite de casos - o comunicaciones, según el lenguaje empleado por la Carta - en los que se aleguen violaciones a los derechos humanos y de los pueblos garantizados por la Carta Africana. El artículo 46 de la Carta faculta a la Comisión para emplear cualquier método apropiado de investigación al abocarse al estudio de los casos, pudiendo recibir información del secretario general de la Unión Africana o de cualquier otra persona que pueda ilustrarla. En este sentido, cualquier individuo, ONG o institución puede presentar información a la Comisión, vía las comunicaciones individuales, aunque el requisito de confidencialidad que la Carta establece limita la intervención formal de estos actores en la labor de la Comisión.

\section{A. Comunicaciones interestatales}

Son aquellos casos sobre violaciones a los derechos humanos, presentados entre Estados, cuyo trámite tiene como propósito principal la

mocratic Development, Penal Reform International, Interights y United Nations Centre for Human Rights, en Murray, Rachel, The African Commission on Human..., cit., nota 35 , p. 15.

58 Ibidem, p. 15.

59 Por ejemplo, $c f r$. International Commission of Jurists, How to Address a Communication to the African Commission, Ginebra, International Commission of Jurists, 1992; incluso, los talleres de trabajo organizados por las ONG previamente a las sesiones de la Comisión Africana.

60 El Reglamento conforme a las últimas reformas de 6 de octubre de 1995 (Rules of Procedure of the African Commission on Human and Peoples' Rights); este instrumento puede consultarse en University of Minnesota, Human Rights Library, http://www1.umn. edu/humanrts/africa/rules.htm (última visita el 10 de septiembre de 2002). 
conciliación de las partes. ${ }^{61}$ El trámite de las comunicaciones interestatales se encuentra establecido en los artículos 47 a 54 de la Carta Africana. Al respecto, el Reglamento de la Comisión distingue entre una comunicación-negociación - negotiation-communication - y entre la comunicación-queja - complaint-communication - ${ }^{62}$ aunque, en realidad, quizá no tenga mucho mérito desarrollar este punto en detalle, puesto que hasta el momento solamente se ha presentado una comunicación interestatal. ${ }^{63}$ No obstante, aunque se trata de un procedimiento que prácticamente no ha sido usado, se tiene una gran expectativa sobre el mismo. ${ }^{64}$

A la comunicación-negociación se refiere el artículo 47 de la Carta, el cual señala que si un Estado parte tiene "buenas razones" —o motivos razonables - para considerar que otro Estado ha violado la Carta, puede hacérselo saber vía escrita al Estado que se considera responsable. Además, también puede enviarse a la Secretaría General de la Unión Africana y al presidente de la Comisión Africana una copia de la correspondencia sostenida entre ambos Estados durante esta primera etapa, pues hasta aquí el procedimiento constituye un intento para solucionar el asunto mediante el diálogo en lugar de propiciar una confrontación. En una segunda etapa, si en el término de tres meses, el asunto no ha sido resuelto satisfactoriamente por los Estados involucrados, cualquiera de ellos puede remitir el caso a la Comisión Africana.

Sin embargo, si un Estado considera que la otra parte no ha cumplido con los principios y derechos de la Carta Africana, puede presentar directamente el caso a la Comisión. Con mayor precisión, es ésta la comunicación-queja a que hemos hecho referencia. Aún así, la Comisión debe usar los recursos necesarios y apropiados para resolver la controversia amigablemente, por lo que las negociaciones bilaterales entre los Estados involucrados son los métodos más adecuados de solución en estas controversias. Si los Estados no logran un acuerdo satisfactorio, la Comisión

61 Cfr. Zanghì, Claudio, La Protezione Internazionale dei Diritti dell'Uomo, Turín, G. Giappichelli Editore, 2002, p. 318.

62 Artículos 93 a 101.

63 Cfr. Communication 227/99 Democratic Republic of the Congo $v$ Burundi, Rwanda and Uganda. En este caso, el Congo alegó casos de múltiples violaciones a la Carta Africana y a los Convenios de Ginebra (sobre derecho humanitario), y acusó a tales países de haber invadido su territorio y provocado una guerra.

64 Cfr. Kodjo, Edem, “The African Charter on Human and Peoples' Rights”, Human Rights Law Journal, vol. 11, núm. 3-4, 1990, p. 281. 
puede elaborar un informe con los hechos y sus recomendaciones -inclusive, puede agregar información proveniente de otras fuentes-, el cual es transmitido a los Estados y a la Asamblea dentro de un periodo razonable a partir del momento en que la Comisión se abocó al caso. El informe, así como cualquier otra medida adoptada con relación a la comunicación interestatal en cuestión, debe permanecer confidencial a menos que la Asamblea General decida en otro sentido. Sin embargo, la Carta Africana no contiene disposición que establezca que ésta debe tomar acción alguna ulteriormente, tampoco existe un mecanismo de supervisión de las recomendaciones elaboradas por la Comisión, aunque cualquier Estado miembro de la Unión Africana podría proponer el tema para discusión durante las sesiones de la Asamblea. ${ }^{65}$

Las facultades de la Comisión Africana durante el trámite de las comunicaciones interestatales son menores a las de un órgano jurisdiccional, pues no puede imponer sus decisiones a los Estados. A pesar de ello, sus resoluciones pueden guiar o determinar el derecho y la práctica de los derechos humanos en África, ${ }^{66}$ aunque el cumplimiento de sus resoluciones dependerá en gran medida de su influencia política y credibilidad. De hecho, la Carta Africana no establece disposición alguna para darle seguimiento a las recomendaciones de la Comisión. En este sentido, la responsabilidad parece recaer en la Asamblea General, no obstante, consideramos que una interpretación más liberal del mandato de la Comisión conduciría a suponer que ella misma tiene facultades para supervisar el cumplimiento de sus propias recomendaciones. De cualquier manera, hacemos notar que una actividad así rompe en gran medida con el principio de la no interferencia ampliamente defendido por los Estados africanos, pues éstos sí deben intervenir si se trata de violaciones a los derechos humanos.

\section{B. “Otras” comunicaciones (individuales)}

La expresión "otras comunicaciones" a que se refieren los artículos 55 a 59 de la Carta Africana, y 102 a 120 del Reglamento de la Comisión, son aquellas presentadas por sujetos distintos a los Estados, por ejemplo,

65 Cfr. Buergenthal, Thomas, International Human Rights in a Nutshell, 2a. ed., Saint Paul, West Publishing, 1995, p. 244.

66 Cfr. Ankumah, Evelyn, The African Commission on Human..., cit., nota 38, p. 23. 
las personas -individual o colectivamente-, organizaciones no gubernamentales, etcétera. Es importante resaltar que la Carta no se refiere a comunicaciones o peticiones "individuales" — como sucede en otros instrumentos internacionales en la materia - sino que simplemente hace una distinción entre aquellas estatales y "otras". Ello podría sugerir una aparente preferencia en la Carta por las comunicaciones interestatales cuyo trámite, sólo por mencionar, se encuentra detalladamente establecido, a diferencia de las "otras".

Las comunicaciones individuales se presentan en la Secretaría de la Comisión en Banjul, Gambia, la cual a su vez las remite a la Comisión Africana. El artículo 56 de la Carta señala cuidadosamente los criterios de admisibilidad de las comunicaciones. No obstante, de la práctica de la Comisión se desprende que casi cualquier persona podría presentar casi cualquier comunicación.

Los requisitos formales de admisibilidad son casi los mismos que aquellos establecidos por otros instrumentos internacionales, aunque si se les compara son más numerosos que los necesarios para analizar la admisibilidad de las comunicaciones interestatales en el sistema africano. Básicamente, la comunicación individual debe indiciar quién es el autor -incluso si se solicita mantener el anonimato es necesario- y ser compatible con la Carta de la Organización de la Unidad Africana - ahora Unión Africana- y la Carta Africana - por lo tanto, se trata de un requisito de contenido bastante indeterminado- Las comunicaciones presentadas a la Comisión no deben estar escritas en un lenguaje "insultante" en contra del Estado responsable y sus instituciones, o contra la Unión Africana; y no deben estar basadas únicamente en información proporcionada por los medios de comunicación - aunque, evidentemente, este tipo de información puede servir de soporte si se trata de hechos notorios y públicos-. Asimismo, las comunicaciones serán admitidas una vez que los recursos de jurisdicción interna hayan sido agotados - a menos que sea manifiesto que dichos procedimientos han sido prolongados indebidamente - y si son interpuestas dentro de un plazo razonable a partir de que los recursos de jurisdicción interna hayan sido agotados o desde la fecha en que la Comisión tuvo conocimiento del caso. Un último requisito establece que las comunicaciones no deben referirse a asuntos solucionados por los Estados involucrados de conformidad con los principios de la Carta de las Naciones Unidas, de la Carta de la Organización de la Unidad Africana - Unión Africana- o de la Carta Africana. 
Sin embargo, respecto a éste último, conforme a una interpretación literal, nada impediría a la Comisión Africana conocer de una comunicación que se encontrara también en trámite ante otro órgano internacional, en tanto que el requerimiento se refiere no a su tramitación sino a su decisión. No obstante, la propia Comisión Africana se ha pronunciado por desechar aquellas comunicaciones en trámite ante otra instancia internacional con la finalidad de evitar que un Estado se vea sometido a dos procedimientos distintos que pudieran tener resultados contradictorios, o simplemente para que la responsabilidad internacional no sea declarada ante dos o más instancias por las mismas violaciones, e incluso por los mismos hechos, y que una comunicación que ha sido resuelta de fondo no sea reabierta. ${ }^{67}$

Cada comunicación es asignada a un comisionado quien hace las veces de un relator, o a un grupo de trabajo compuesto hasta por tres comisionados. ${ }^{68}$ El relator o el grupo de trabajo pueden solicitar información adicional al autor o al Estado respectivo antes de elaborar cualquier recomendación a la Comisión respecto a la admisibilidad de la comunicación. ${ }^{69}$ Debe señalarse que aunque la Carta Africana no distingue claramente entre la admisibilidad y el estudio de los méritos, sí establece que la comunicación debe ser transmitida al Estado antes de cualquier pronunciamiento de fondo. ${ }^{70} \mathrm{Si}$ la Comisión considera que la comunicación es inadmisible, lo notifica tanto al autor y al Estado, si a éste ya le hubiera sido transmitida la comunicación. Cuando la comunicación es admisible, se le informa al Estado y se le otorga un plazo de tres meses para presentar cualquier declaración con relación a los hechos del caso y a las medidas que haya adoptado para remediar la situación. Posteriormente, el autor de la comunicación también podrá elaborar sus propias observaciones. ${ }^{71}$ Al Estado puede notificársele hasta por tres veces, y en caso de que no responda a los hechos de la comunicación, la Comisión procederá

67 Cfr. Communication 15/88 Mpaka-Nsusu Andre Alphonse v. Zaire, p. 1, y Communication 69/92 Amnesty International $v$. Tunisia, p. 1.

68 Artículo 115 del Reglamento de la Comisión.

69 Artículo 104 y 117 del Reglamento de la Comisión.

70 Artículo 57 de la Carta Africana. Cfr. también los artículos 55, 56, 58 y 59 de la Carta.

71 Artículos 90 y 119, párrafos 2o. y 3o. del Reglamento de la Comisión. 
al estudio de los méritos con base en la evidencia y pruebas de que disponga. ${ }^{72}$

Previamente al estudio del fondo de la comunicación, la Comisión puede solicitar al Estado la adopción de medidas provisionales a fin de evitar daños irreparables a la víctima de las violaciones alegadas. La adopción de estas medidas no implica un prejuzgamiento sobre el fondo del caso. ${ }^{73}$ Debe hacerse notar que la Carta Africana no faculta expresamente a la Comisión para sugerir a los Estados partes la adopción de medidas provisionales, sin embargo, a través de una interpretación amplia del artículo 46 de la Carta Africana, la Comisión ha logrado enfrentar situaciones de urgencia a través de la aplicación de este tipo de medidas. Dicho artículo faculta a la Comisión a recurrir a cualquier método de investigación durante el trámite de los casos.

Asimismo, la Comisión puede llevar a cabo investigaciones in situ en el territorio del Estado en contra del cual se hubiere presentado la comunicación. En realidad, este método de investigación no se encuentra previsto por la Carta. No obstante, a través de una interpretación pro homine, la Comisión se ha fundado en el artículo 46 de la Carta ya señalado para solicitar a los Estados que le permitan hacer investigaciones en sus territorios, sobre todo si se trata de una situación de emergencia o urgencia. ${ }^{74}$ Por otro lado, aunque en la Carta Africana no se encuentra expresamente estipulado, la Comisión puede procurar la solución amistosa de la controversia basada en el respeto de los derechos humanos y las libertades fundamentales reconocidos en la Carta. ${ }^{75}$ Aunque, evidentemente, un prerrequisito para lograr este objetivo es la buena fe de las partes involucradas y su voluntad para participar en el diálogo. ${ }^{76}$

La Comisión puede decidir celebrar audiencias durante el estudio de los méritos de la comunicación, aunque debe hacerse notar que ni la Car-

72 Artículo 119, párrafo 4o. del Reglamento.

73 Artículo 111 del Reglamento de la Comisión.

74 Como aquellas señaladas por el artículo 58 de la Carta.

75 Artículos 52 de la Carta y 98 del Reglamento. Sin embargo, esta disposición se encuentra prevista para el trámite de las comunicaciones interestatales y no para las individuales. No obstante, si se interpreta conforme a otros instrumentos internacionales y según el objeto y fin de la propia Carta Africana, la Comisión puede ofrecer un arreglo amistoso en cualquier tipo de procedimiento.

76 Cfr. Communications 25/89, 47/90, 56/91, 100/93 (Joined), Free Legal Assistance Group, Lawyer's Committee for Human Rights, Union Interafricaine des Droits de l'Homme, Les Temoins de Jehovah $v$. Zaire, párrafo 39. 
ta ni el Reglamento lo prevén. ${ }^{77}$ No obstante, sería contrario al derecho de audiencia que las partes no pudieran ser oídas por la Comisión, sobre todo si se trata de las víctimas. A las audiencias asisten tanto los representantes de los Estados como de las víctimas, incluso éstas personalmente. ${ }^{78}$

En la interpretación y aplicación de la Carta Africana, la Comisión debe "inspirarse" en los instrumentos, principios y estándares internacionales y regionales sobre la materia. ${ }^{79}$ En este sentido, una vez que ha estudiado el fondo del asunto, en su decisión de mérito la Comisión debe elaborar recomendaciones dirigidas al Estado responsable en las que señale las medidas apropiadas que deben adoptarse para remediar las violaciones cometidas. En tanto que la Comisión Africana no es un órgano jurisdiccional, sus recomendaciones no son vinculatorias, ${ }^{80}$ por lo tanto, el cumplimiento de sus recomendaciones depende en gran medida de la buena disposición del Estado de que se trate. ${ }^{81}$

En cuanto a las reparaciones, debe mencionarse que ni la Carta Africana ni el Reglamento señalan específicamente que la Comisión puede ordenar este tipo de medidas como resultado del trámite de las comunicaciones individuales. De hecho, en la Carta Africana existe una laguna y las reparaciones solamente están previstas para "casos especiales" que revelen la existencia de violaciones graves y masivas a los derechos humanos y de los pueblos. ${ }^{82}$ Sin embargo, como el artículo 45 de la Carta señala que la Comisión tiene facultad para formular y establecer princi-

77 El Reglamento solamente establece el derecho de audiencia para los Estados cuando se trata de comunicaciones interestatales; $c f r$. artículo 100, párrafo 10.

78 Cfr. Odinkalu, Chidi Anselm y Christensen, Camilla, "The African Commission on Human and Peoples' Rights...”, cit., nota 53, p. 273.

79 Cfr. artículos 60 y 61 de la Carta, y Communication 241/2001 Purohit and Moore $v$. The Gambia, párrafo 47.

80 Cfr. "Account of Internal Legislation of Nigeria and the Dispositions of the Charter of African Human and Peoples' Rights", Final Communiqué of the Second Extraordinary Session of the African Commission on Human and Peoples' Rights. También, Information Sheet núm. 3: Communication Procedure, p. 8, African Commission on Human and Peoples' Rights, http://www.achpr.org/ACHPR_inf._sheet_no.3.doc (última visita el 10 de abril de 2003).

81 Cfr. Symonides, Janusz y Volodin, Vladimir (comps.), A Guide to Human Rights. Institutions, Standards, Procedures, París, UNESCO, 2001, p. 32.

82 Son las situaciones previstas por el artículo 58 de la Carta. Cfr. Benedek, Wolfgang, "The African Charter on Human and Peoples' Rights...", cit., nota 54, p. 31. 
pios y normas con el objetivo de resolver problemas jurídicos concernientes a los derechos, entonces puede interpretarse que sí tiene facultad para adoptar medidas efectivas y relevantes para remediar las violaciones. ${ }^{83}$ Consecuentemente, la Comisión ha considerado que puede darle seguimiento a sus recomendaciones para asegurarse de que los Estados cumplan con ellas. ${ }^{84}$

En sus primeros años, en la mayoría de los casos la Comisión simplemente declaraba violados los artículos de la Carta Africana, sin hacer mención alguna a las reparaciones. ${ }^{85}$ Actualmente, la Comisión Africana ha empezado a señalar recomendaciones que incluyen reparaciones, aunque esta práctica no ha sido constante. Además, sólo la menor parte de las reparaciones ordenadas han sido de carácter económico, ${ }^{86}$ aunque úl-

83 Cfr. Odinkalu, Chidi Anselm y Christensen, Camilla, "The African Commission on Human...", cit., nota 53, p. 242.

84 Cfr. Communication 87/93 The Constitutional Rights Project (in respect of Zamani Lakwot and 6 others) $v$. Nigeria, último párrafo.

85 Por ejemplo, Communications 64/92, 68/92 y 78/92 Krischna Achuthan, Amnesty International, Amnesty International v. Malawi, Eighth Annual Activity Report of the African Commission on Human and Peoples' Rights 1994-1995, anexo VI, pp. 387-389.

86 Fue hasta 2000 cuando se presentó el primer caso en el que una víctima solicitó compensación económica; $c f r$. Communication 59/91 Embga Mekongo Louis $v$. Cameroon, párrafo 2o. El caso fue remitido a las instancias locales para determinar el monto de la indemnización. Ese mismo año, la Comisión recomendó el pago de una compensación a las viudas y a los beneficiarios de las víctimas; cfr. Communications 54/91, 98/93, 164/97 a 196/97, 210/98 Malawi African Association, Amnesty International, Ms. Sarr Diop, Union Interafricaine des Droits de l'Homme and RADDHO, Collectif des Veuves et Ayants-droit, Association Mauritanienne des Droits de l'Homme v. Mauritania, pp. 138-162. En una comunicación en la cual se declararon violados derechos de la tercera generación, señaló como reparación una compensación económica en favor de las víctimas; cfr. Communication 155/96..., cit., nota 17, pp. 31-44. Compárese, por ejemplo, con la práctica de los órganos interamericanos de derechos humanos. En principio, la reparación incluye siempre una compensación de tipo económico, además de otras que se estimen pertinentes ( $c f r$. artículo 63, párrafo 1o., de la Convención Americana). Esto es común también ante la Corte Europea de Derechos Humanos con base en el concepto de "justa satisfacción" ( $c f r$. artículo 41 de la Convención Europea), aunque debe señalarse que ha habido casos en los que este tribunal ha determinado que la sola sentencia constituye suficiente reparación, particularmente tratándose de daño inmaterial y, por lo tanto, no ha concedido el pago de indemnizaciones económicas por ese concepto; $c f r$., a manera de ejemplo, Case of Radovanovic $v$. Austria, Judgement (Just Satisfaction), 16 de diciembre de 2004, disposición primera de la sentencia. Cabe observar que la Corte Europea ordenó el pago de determinada cantidad pero sólo por los gastos y costas que la víctima había efectuado como consecuencia de las violaciones alegadas. 
timamente la Comisión ha mostrado cierta voluntad de tomar medidas más activas e insistentes. Sin embargo, de los casos decididos hasta el momento, es difícil deducir una práctica uniforme en cuanto al tema, por ejemplo, en algunos casos ha elaborado recomendaciones que parecen ser órdenes directas, en otros, incluso se ha rehusado a considerar las solicitudes por daños presentadas por los peticionarios; además, en otras comunicaciones se conforma con información extraoficial sobre el aparente cumplimiento de las recomendaciones, para dar por terminado el procedimiento.

Las resoluciones sobre las comunicaciones son incluidas en cada informe anual de actividades de la Comisión, el cual se presenta a la Asamblea General. ${ }^{87} \mathrm{Si}$ el informe es aprobado por ésta, las recomendaciones se vuelven obligatorias para los Estados. ${ }^{88}$ Esta práctica se encuentra establecida en el artículo 59 de la Carta, el cual señala que todas las "medidas" tomadas dentro del marco del capítulo relativo a "Otras comunicaciones" 89 serán confidenciales hasta el momento en que la Asamblea General decida lo contrario; asimismo, que el informe anual que haga referencia a ellas será publicado por el presidente de la Comisión cuando lo apruebe la Asamblea. Durante mucho tiempo, la Comisión interpretó restrictivamente lo que debía entenderse como "medidas", en este sentido, no podían revelarse los nombres de los Estados involucrados, describirse la naturaleza de los casos ni hacer mención de la etapa del trámite en el que se encontraban. ${ }^{90}$ Ello generó restricciones al efecto disuasorio necesario para la prevención y sanción de las violaciones a derechos humanos. Además, la propia Comisión estableció un obstáculo para informar sobre sus actividades, lo que a su vez protegió indirectamente a los Estados responsables de tales violaciones. Lo anterior en parte propició

87 Artículo 54 de la Carta.

88 Cfr. Information Sheet núm. 3: Communication Procedure..., cit., nota 80, p. 8.

89 Es decir, aquellas quejas y denuncias distintas a las interestatales.

90 Lo anterior se desprende del análisis de los seis primeros informes anuales, $c f r$. First Activity Report of the African Commission on Human and Peoples' Rights 1987-1988, párrafo 26; Second Activity Report of the African Commission on Human and Peoples' Rights 1988-1989, párrafo 35; Third Activity Report of the African Commission on Human and Peoples' Rights 1989-1990, párrafo 24; Fourth Annual Activity Report of the African Commission on Human and Peoples' Rights 1990-1991, párrafo 13; Fifth Annual Activity Report of the African Commission on Human and Peoples' Rights 1991-1992, párrafo 23; y, Sixth Annual Activity Report of the African Commission on Human and Peoples’ Rights 1992-1993, párrafo 29. 
que se forjara una cierta percepción de inefectividad y la incertidumbre de los resultados de su trabajo. Esto, además, no nos permite proporcionar datos precisos sobre, por ejemplo, el número de casos estudiados por la Comisión, el tipo de violaciones más frecuentes que se alegan, el registro de Estados en contra de los cuales se han presentado, las medidas provisionales ordenadas, etcétera. ${ }^{91}$

No obstante lo mencionado, ha habido importantes avances sobre el tema. Es interesante notar el giro dado por la Comisión Africana en la interpretación sobre lo que la confidencialidad implica. Por ejemplo, en su segundo informe anual de actividades, la Comisión hubo señalado que los casos decididos durante el periodo comprendido por el informe "permanecen en confidencialidad de conformidad con el artículo 59 de la Carta Africana". ${ }^{92}$ Sin embargo, en su séptimo informe de actividades, con fundamento en el mismo artículo, la Comisión mencionó que "los detalles de las comunicaciones... se encuentran contenidas en el anexo IX", ${ }^{93}$ de tal manera que a partir de ese informe incluye las decisiones completas sobre los casos analizados durante los periodos de sesiones. ${ }^{94}$

91 Incluso, en el sitio oficial de la Comisión Africana solamente se encuentran publicados los casos a partir de su décimo Informe Anual de Actividades; cfr. http://www .achpr.org/english/_info/index_activity_en.html (última visita el 17 de agosto de 2007). Por lo que respecta a los casos anteriores existe una obra que los recopila desde su primer informe de actividades hasta el duodécimo, sin embargo, no se trata de una publicación oficial. En este sentido, $c f r$. Murray, Rachel y Evans, Malcolm (comps.), Documents of the African Commission on Human and Peoples' Rights, Documents of the African Commission on Human and Peoples' Rights, Oxford, Hart Publishing, 2001.

92 "(The decisions, for the time being) remain confidential in conformity with Article 59 of the African Charter", Second Activity Report..., cit., nota 90, p. 177; además, Sixth Annual Activity Report..., cit., nota 90, p. 247.

93 "(In accordance with article 59 of the African Charter), the details of the (above-mentioned) communications are contained in Annex IX", Seventh Annual Activity Report of the African Commission on Human and Peoples' Rights 1993-1994, anexo IX, pp. 337-350.

$94 C f r$. en el mismo sentido, Eighth Annual Activity Report of the African Commission on Human and Peoples' Rights 1994-1995, anexo VI, pp. 382-399; Ninth Annual Activity Report of the African Commission on Human and Peoples' Rights 1995-1996, anexo VIII, pp. 444-456; Tenth Annual Activity Report of the African Commission on Human and Peoples' Rights 1996-1997, anexo X, pp. 551-574; Eleventh Annual Activity Report of the African Commission on Human and Peoples' Rights 1998-1999, anexo II; Twelfth Annual Activity Report of the African Commission on Human and Peoples' Rights 1998-1999, anexo V, pp. 712-754; Thirteenth Annual Activity Report of the African Commission on Human and Peoples' Rights 1999-2000, anexo V, pp. 53-162; Four- 
Inclusive, la Comisión ha empezado a hacer públicas las observaciones de los Estados a sus recomendaciones. ${ }^{95}$ No obstante, los informes en las que se encuentran pueden hacerse públicos sólo cuando hayan sido aprobados por la Asamblea. Es notable la cantidad y la calidad de información que al respecto contienen los últimos informes anuales. Empero, subsiste la percepción de que la Comisión Africana es temerosa de dar a conocer sus decisiones, sobre todo tratándose de peticiones individuales, pues se expone a la crítica y condena de los gobiernos africanos y de la sociedad civil. ${ }^{96}$ No obstante el importante desarrollo logrado respecto a la publicidad, el concepto de la confidencialidad seguirá siendo problemático, siempre y cuando la Asamblea General ejerza el monopolio de la autorización de las decisiones de la Comisión. La interpretación restrictiva del concepto priva a la Carta de gran parte de su intención. La práctica de otros organismos internacionales ha demostrado que la publicidad y la sanción moral de la opinión pública gozan de un mayor efecto persuasivo en la prevención de violaciones futuras y obligan a los Estados a respetar los derechos humanos. ${ }^{97}$

teenth Annual Activity Report of the African Commission on Human and Peoples' Rights 2000-2001, anexo V, pp. 27-105; Fifteenth Annual Activity Report of the African Commission on Human and Peoples' Rights 2001-2002, anexo V, pp. 30-55; y Sixteenth Annual Activity Report 2002-2003, anexo VII, pp. 36-102; Seventeenth Annual Activity Report of the African Commission on Human and Peoples' Rights 2003-2004, anexo VII, pp. 66-140; Eighteenth Annual Activity Report of the African Commission on Human and Peoples' Rights 2004-2005, anexo III, pp. 12-40; Twentieth Annual Activity Report of the African Commission on Human and Peoples' Rights 2005-2006, anexo IV, pp. 95-140, Twenty-First Annual Activity Report of the African Commission on Human and Peoples' Rights, anexo II, pp. 27-111; Twenty-Second Activity Report of the African Commission on Human and Peoples' Rights, anexo II, pp. 29-57.

95 Por ejemplo, las observaciones del Estado a Communication 245/2002, Zimbabwe Human Rights NGO Forum/Zimbabwe, Twenty-First Annual Activity Report of the African Commission on Human and Peoples' Rights..., cit., nota anterior, anexo II, pp. 104-111.

96 Cfr. Murray, Rachel, "The African Charter on Human and Peoples' Rights 1987-2000: An Overview of its Progress and Problems", African Human Rights Law Journal, Sudáfrica, vol. 1, núm. 1, 2001, p. 11.

97 Cfr. Vasak, Karel, "Los derechos humanos como realidad legal", en id. (comp.), Las dimensiones internacionales de los derechos humanos, vol. I, Barcelona, Serbal-UNESCO, 1984, p. 35. En este sentido, son notables los esfuerzos de la Comisión y Corte interamericanas de Derechos Humanos. 


\section{Informes periódicos}

El artículo 62 de la Carta Africana establece que los Estados partes deben presentar cada dos años un informe sobre las medidas legislativas o de otro tipo que hayan adoptado a fin de dar efecto a los derechos y libertades reconocidos y garantizados por la Carta. Sin embargo, este artículo no es muy preciso y, curiosamente, no señala a qué instancia deben remitirse tales informes. El mandato de la Comisión Africana, determinado por el artículo 45 de la Carta, no incluye la facultad para revisar los informes periódicos, sin embargo, siendo el órgano encargado de supervisar la implementación de la Carta Africana, parecería que sí forma parte de sus funciones. Para colmar la laguna, haciendo una interpretación conjunta de los artículos 45 y 46 de la Carta, ${ }^{98}$ la Comisión tuvo que recomendar a la Asamblea General de la entonces Organización de la Unidad Africana que la facultara para recibir y analizar los informes. ${ }^{99}$ A fin de que los Estados cumplan de forma más satisfactoria con esta obligación, la Comisión emitió una Guía para la Presentación de Informes Periódicos Nacionales que pretende que estos documentos sean claros, organizados y precisos, y al mismo tiempo, ayudar a los funcionarios del gobierno a elaborar informes que sean adecuados tanto en su alcance como en su contenido. ${ }^{100}$ No obstante, esta guía ha sido muy criticada por ser muy larga, demasiado detallada en algunos aspectos y ambigua en otras áreas. ${ }^{101}$ Adicionalmente, carece de uniformidad en al-

98 Cfr. Information Sheet núm. 4: State Reporting Procedure, p. 1, African Commission on Human and Peoples' Rights, http://www.achpr.org/ACHPR_inf._sheet_No.4.doc (última visita el 10 de abril de 2003).

99 Cfr. "Recommendation on Periodic Reports", p. 10. Cfr. la autorización de la Asamblea General AHG/Res.176(XXIV), Second Activity Report of the African Commission on Human and Peoples' Rights 1988-1989, párrafo 31.

100 Cfr. "Guidelines for National Periodic Reports", pp. 49-79; también Alston, Philip, "The International Covenant on Economic, Social and Cultural Rights", en Boven, Theo van et al., Manual on Human Rights Reporting. Under Six Major International Human Rights Instruments, Nueva York, United Nations Centre for Human Rights-UNITAR, 1991, p. 40, y "General Guidelines Regarding the Form and Contents of Reports from States on Civil and Political Rights", párrafo 7.

101 Cfr. Murray, Rachel, The African Commission on Human..., cit., nota 35, p. 16. 
gunos temas y tiende a ser repetitiva, en cierta forma, es más confusa que útil. ${ }^{102}$

Aunque la guía provee cierta orientación concreta a los Estados y al mismo tiempo facilita la labor de la Comisión en el análisis de los informes, lo criticable es su imprecisión y al mismo tiempo excesivo detalle en ciertos aspectos, lo cual es poco favorable para el mecanismo en la práctica. Por eso, a instancia de varios Estados africanos y a solicitud de diversas $\mathrm{ONG}$, se inició la discusión sobre una probable enmienda a la Guía, la cual tuvo lugar en 1997. ${ }^{103}$ En contraste notable con la guía original, la enmienda consiste en once puntos que los Estados deben tomar en cuenta al elaborar los informes. ${ }^{104}$ No obstante, el patrón de presentación de los informes ha seguido careciendo de uniformidad. Estos documentos siempre variaron notablemente en su calidad, estilo y longitud, y lo mismo continua aún con la enmienda. La guía ahora es vaga en su totalidad y falla en su intento de requerir información que, aunque es práctica, carece de sustancia. La adopción de la enmienda solamente ha servido para resaltar lo que ha sido la práctica de los Estados y, en cierta forma, para legitimarla. Por lo tanto, el factor principal no es la guía en sí sino la voluntad de los Estados para comprometerse con el sistema.

Los informes son examinados públicamente por la Comisión, y en caso de realizarse mediante audiencia, cualquier comisionado puede formular preguntas u observaciones al representante o agente del Estado que se encuentre presente para tal efecto. Las ONG o particulares pueden, asimismo, presentar información adicional — no oficial- a la Co-

102 En el mismo sentido, cfr. Gaer, Felice, "First Fruits: Reporting by States under the African Charter on Human and Peoples' Rights", Netherlands Quarterly on Human Rights, Países Bajos, vol. 1, 1992, p. 31, y Flinterman, Cees y Ankumah, Evelyn, "The African Charter on Human and Peoples' Rights", en Hannum, Hurst, Guide to International Human Rights Practice, 3a. ed., Ardsley, Transnational Publishers, 1999, p. 169.

103 Esta reforma se inspiró en las recomendaciones y comentarios recogidos durante la celebración de dos seminarios sobre el sistema de informes de la Carta. Cfr. Evans, Malcolm e Ige, Tokunbo et al., "The reporting mechanism of the African Charter", en Evans, Malcolm y Murray, Rachel (comps.), The African Charter on Human ..., cit., nota 16 , pp. 47 y 48.

104 Cfr. "Guidelines to Periodic Reporting Under Article 62 of the African Charter on Human and Peoples' Rights", African Commission on Human and Peoples' Rights, http://www.achpr.org/html/statereports.html (última visita el 10 de abril de 2003). 
misión para ser utilizada durante el estudio del informe respectivo. ${ }^{105} \mathrm{Al}$ final de este procedimiento, la Comisión Africana elabora observaciones a los Estados a manera más precisa, se trata de sugerencias para mejorar el cumplimiento de los derechos humanos y de los pueblos garantizados por la Carta. Una vez que han sido enviadas las observaciones a los Estados, éstos deben presentar información adicional, y sus comentarios a las observaciones finales de la Comisión. Además, ésta puede transmitir a la Asamblea General sus observaciones y copias de los informes periódicos así como los comentarios de los Estados, ${ }^{106}$ es decir, ésta no es una obligación y se encuentra sujeta a la discrecionalidad de la Comisión poner tal información en conocimiento de la Asamblea General.

Sin embargo, el mayor problema del mecanismo de informes es que ni la Carta ni el Reglamento hacen referencia alguna a las consecuencias jurídicas que eventualmente puede conllevar el que los Estados ignoren las observaciones de la Comisión. Como no se trata de un procedimiento contradictorio, las sugerencias y comentarios de este órgano no son obligatorios en sentido estricto $\mathrm{y}$, por lo tanto, no conllevan responsabilidad internacional.

\section{Otras funciones}

La Comisión Africana tiene facultades para interpretar las disposiciones de la Carta a solicitud de cualquier Estado parte, de algún órgano de la Unión Africana o cualquier organización africana legalmente reconocida por ésta. ${ }^{107}$ Debe resaltarse que esta función le haya sido asignada a la Comisión, pues normalmente se deposita en un órgano judicial. No obstante, al momento de adoptarse la Carta no se encontraba contemplada ninguna institución judicial, por lo cual esta facultad corresponde a la Comisión. Sin embargo, hasta el momento no ha sido emitida opinión consultiva alguna.

Por otro lado, la Comisión puede llevar a cabo cualquier otra función que le asigne la Asamblea General de la Unión Africana. ${ }^{108}$ Sobre este punto en particular, no se encuentra específicamente establecido qué otro

105 Cfr. Evans, Malcolm e Ige, Tokunbo et al., "The reporting mechanism of the African Charter", en Evans, Malcolm y Murray, Rachel (comps.), op. cit., nota 16, p. 57.

106 Artículos 85, párrafo 3o., y 86, párrafos 1o. y 2o., del Reglamento.

107 Artículo 45, párrafo 3o., de la Carta.

108 Artículo 45, párrafo 4o., de la Carta. 
tipo de actividades, sin embargo, en varias ocasiones les ha sido solicitado a los comisionados que participen, por ejemplo, como observadores electorales en distintos países africanos, particularmente en las misiones desplegadas por la entonces Organización de la Unidad Africana. ${ }^{109} \mathrm{De}$ cualquier manera, el amplio mandato de la Comisión hace prácticamente innecesario buscar la aprobación de la Asamblea sobre otras iniciativas de gran trascendencia. ${ }^{110}$

\section{LA CORTE AFRICANA DE DERECHOS HUMANOS Y DE LOS PUEBLOS}

Este órgano judicial representa el último de los esfuerzos institucionales de la Unión Africana en su compromiso con los derechos humanos. Como ya habíamos señalado, la Carta solamente contempla como órgano promotor y protector de los derechos humanos a la Comisión, un órgano de naturaleza evidentemente no judicial y con restringidas facultades para influir eficazmente a los Estados. Aunque ello por sí mismo no ha tenido resultados negativos en la efectividad del sistema africano, durante mucho tiempo se presionó y se insistió para que se contara además con un órgano similar a las cortes Europea e Interamericana con la idea de que una instancia judicial supranacional por su propia naturaleza causara un mayor impacto sobre la conducta de los Estados, al menos por lo que se refiere a la fuerza vinculante de sus decisiones. ${ }^{111}$

La Corte Africana de Derechos Humanos y de los Pueblos (Corte o Corte Africana) fue creada mediante el Protocolo de la Carta Africana de Derechos Humanos y de los Pueblos para el Establecimiento de una Cor-

109 Cfr. Murray, Rachel, The African Commission on Human..., cit., nota 35, p. 26.

110 Cfr. Flinterman, Cees y Ankumah, Evelyn, "The African Charter on Human...", cit., nota 102, pp. 169 y 170. Sólo por mencionar, en 1990, durante el 17o. periodo de sesiones la Comisión Africana ofreció sus buenos oficios a Liberia, país en donde prevalecía una situación de violaciones masivas a los derechos humanos debido a un conflicto armado entre el gobierno y fuerzas rebeldes; $c f r$. Umozurike, U. Oji, "The African Commission on Human and Peoples' Rights", Review of the African Commission on Human and Peoples' Rights, Gambia, vol. 1, 1991, p. 12.

111 Cfr. Naldi, Gino J. y Magliveras, Konstantinos, "Reinforcing the African System of Human Rights: The Protocol on the Establishment of a Regional Court on Human and Peoples' Rights", Netherlands Quarterly of Human Rights, Países Bajos, vol. 16, núm. 4, 1998, p. 456. 
te Africana de Derechos Humanos y de los Pueblos (en adelante, sólo "Protocolo"), adoptado en 1998 y en vigor desde el 25 de enero de 2004. ${ }^{112}$ Sus primeros once jueces fueron elegidos en enero de 2006 y aunque la Corte ya se encuentra en funciones, su establecimiento total ha demorado por casi tres años, principalmente debido a los problemas financieros de la Unión Africana. ${ }^{13}$ La Corte inicialmente celebró sus primeras sesiones en las sede de la Comisión Africana y de la Unión Africana -Banjul y Addis Abeba, respectivamente_- ${ }^{114}$

Debe mencionarse un aspecto muy relevante respecto a su funcionamiento. La Unión Africana decidió llevar a cabo la fusión de la Corte Africana de Justicia y de la Corte Africana de Derechos Humanos y de los Pueblos. ${ }^{115}$ Aunque este proceso todavía se encuentra en discusión con relación a la forma en que habrá de realizarse, destaca una propuesta conforme a la cual la Corte Africana será una especie de sala especializada de la Corte Africana de Justicia, aunque conservando plenamente sus facultades, competencia, jurisdicción y conformación. Como sea que tenga lugar la integración, la Corte tendrá su sede en Arusha, Tanzania. ${ }^{116}$

Por el momento, el Protocolo representa solamente un avance institucional, y no sustantivo, respecto a la Carta Africana, no obstante, su mandato en sí mismo tendrá un impacto importante sobre los Estados africanos. ${ }^{117}$ Algunos de sus puntos más revelantes se refieren a la adju-

112 Para un desarrollo más amplio del tema, cfr. Harrington, Julia, "The African Court on Human and Peoples' Rights", en Evans, Malcolm y Murray, Rachel (comps.), op. cit., nota 16, pp. 308-315.

113 El juramento de los jueces tuvo lugar durante la 7a. sesión ordinaria de la Asamblea de la Unión Africana celebrada en Banjul, Gambia, el 2 de julio de 2006.

114 Cfr. "Activity Report of the Court for 2006" - primer informe anual de actividades-Assembly/AU/8 (VIII), pp. 3 y 4.

$115 C f r$. Decision on the Seats of the African Union, Assembly/AU/Dec.45 (III), párrafo operativo 40 .

116 Por el momento, la Corte Africana de Derechos Humanos y de los Pueblos se encuentra alojada en el Centro Internacional de Conferencias de Arusha (AICC, por sus siglas en inglés), aunque el gobierno de ese país tiene previsto destinarle el edificio que actualmente ocupa el Tribunal Penal Internacional para Rwanda, en esa misma ciudad, el cual terminará sus funciones en 2008. Cfr. Mwita, Sosthenes, "Tanzania Ratifies: Arusha to Host", ACC Newsletter, núm. 5, abril de 2006, Coalition for an Effective African Court on Human and Peoples' Rights, http://www.africancourtcoalition.org/content_fi les/files/ACCNewsletterEdition5.pdf (última visita en 17 de agosto de 2007).

117 Cfr. Nmehielle, Vincent O., "Development of the African Human Rights System in the Last Decade", Human Rights Brief, Washington, vol. 11, núm. 3, 2004, p. 8. Ha- 
dicación efectiva de la Corte, a la posibilidad de ordenar reparaciones y dictar sentencias plenamente obligatorias, y a la facultad para responsabilizar a los Estados que violen derechos humanos. ${ }^{118}$ La propia Unión Africana ha expresado que este tribunal representa un órgano clave en el sistema africano, en tanto que complementa el mandato de protección de la Comisión y refuerza su compromiso de respeto de los derechos humanos y los valores fundamentales de tolerancia, solidaridad, equidad de género y acción humanitaria en el continente africano. ${ }^{119}$

En el contexto africano, la Corte se establece como un mecanismo a través del cual se pretende hacer los derechos humanos plenamente exigibles. En este sentido, este tribunal toma algunas de las características más relevantes de las cortes Europea e Interamericana de Derechos Humanos, aunque también posee rasgos originales. Sin embargo, existe un gran escepticismo sobre su futuro éxito, por ejemplo, no es muy convincente la afirmación de que los Estados africanos cumplirán sus sentencias más que las decisiones de la Comisión por el sólo hecho de tratarse de una instancia judicial. ${ }^{120}$ Incluso, hay quienes consideran que el Protocolo no refleja compromisos honestos y que los Estados africanos solamente buscaron protegerse ellos mismos del escrutinio público. ${ }^{121}$ No obstante, es remarcable la gran convocatoria que se generó al entrar en vigor el Protocolo. Fueron varios los países que se ofrecieron como sede de la Corte y más los que se apresuraron a nominar a sus candidatos para jueces. En este sentido, hay quienes estiman que este proceso fue una se-

bría que esperar a que la Corte Africana empiece a interpretar y aplicar la Carta para que a través de su jurisprudencia pudiera haber un desarrollo sustantivo.

118 Cfr. Mugwanya, George William, Human Rights in Africa: Enhancing Human Rights Through the African Regional Human Rights System, Ardsley, Transnational Publishers, 2003, p. 316. Incluso, se ha llegado a considerar que el Protocolo es el "eslabón perdido" del sistema africano; $c f r$. Akinseye-George, Yemi, "New Trends in African human rights law: prospects of an African Court of Human Rights", University of Miami International and Comparative Law Review, Washington, núm. 10, 2002, p. 168.

119 Cfr. Press Release núm. 121/2003, "The Protocol on the African Court on Human and Peoples' Rights to Come into Force Soon", African Union, http://www.africa-union. org/home/welcome.htm (última visita: 11 de noviembre de 2004).

120 See Österdahl, Inger, Implementing Human Rights in Africa, Uppsala, Iustus Förlag, 2002, p. 32. Sería menos complicado —y económico- cumplir desde el principio con las recomendaciones de la Comisión en lugar de crear todo una nueva maquinaria que estaría condenada a fracasar si los Estados africanos simplemente no están dispuestos a cumplir con cualquier decisión sin importar el órgano que las haya emitido.

121 Cfr. Harrington, Julia, "The African Court on Human...”, cit., nota 112, p. 316. 
ñal de la determinación de los Estados partes del Protocolo para asegurar el pronto establecimiento de la Corte. ${ }^{122}$ Actualmente, este instrumento ha sido firmado por cuarenta y nueve de los cincuenta y tres Estados miembros de la Unión Africana, de los cuales veintitrés ya lo han ratificado. ${ }^{123}$

Por otro lado, debe remarcarse que se desconoce en gran medida el trabajo que se encuentra realizando la Corte. Hasta el momento, este tribunal solamente ha emitido un informe anual de actividades en el cual se limita a describir actividades mayormente de tipo administrativo. Entre otros, destacan sus evaluaciones y recomendaciones para realizar efectivamente su mandato. La Corte hace referencia a la excesiva dependencia de la Comisión de la Unión Africana para la toma de algunas decisiones, a obstáculos burocráticos y a la falta de una sede permanente. ${ }^{124}$ Además de estos elementos, no existe otro tipo de información oficial que permita hacer un análisis más completo. Por lo anterior, a continuación solamente haremos mención a sus rasgos orgánicos y procesales más relevantes, principalmente conforme al Protocolo y, cuando resulte pertinente, se comparará con otros órganos judiciales internacionales en la materia.

Este tribunal se integra con once jueces propuestos y elegidos por los Estados miembros de la Unión Africana. Actualmente sus jueces son nacionales de Burundi, Mali, Ghana, Libia, Senegal, Uganda, Lesotho, Ruanda, Sudáfrica, Argelia y Burkina Faso. Éstos tienen un mandato de seis años, pudiendo ser reelegidos por una sola vez.

La Corte puede decretar medidas provisionales, y sus fallos son definitivos, aunque existe la posibilidad de revisión si se dan las circunstancias necesarias para ello. Sus decisiones son obligatorias y los Estados partes están comprometidos a ejecutar las sentencias que emita. ${ }^{125}$ En

122 Cfr. The Coalition for an Effective African Court on Human and Peoples' Rights, "Legal and Institucional Issues Arising from the Decision by the Assembly of Heads of State and Government of the African Union to Integrate the African Court on Human and Peoples' Rights and the Court of Justice of the African Union", Justice Initiative, http://www.justiceinitiative.org/db/resource2?res_id=102364, p. 5 (última visita el 17 de agosto de 2007).

123 Conforme a la información publicada en el sitio oficial de la Unión Africana, actualizada al 26 de mayo de 2007, http://www.africa-union.org/root/au/Documents/Trea ties/List/Protocol\%20on\%20the\%20African\%20Court\%20on\%20Human\%20and\%20Pe oples\%20Rights.pdf.

124 “Activity Report...", cit., nota 114, pp. 8 y 9.

125 Artículos 11, 12, 15, 27 a 30 del Protocolo. 
cuanto a su mandato, la Corte Africana tiene dos funciones: una contenciosa y una consultiva.

\section{Comunicaciones individuales e interestatales}

Con relación a su función contenciosa, la Corte conoce de casos presentados por la Comisión, los Estados partes y las organizaciones gubernamentales e individuos - cuando el Estado presuntamente responsable haya aceptado previa y expresamente la competencia de la Corte para recibir este tipo de comunicaciones - que versen sobre la interpretación y aplicación de la Carta Africana, el Protocolo y cualquier otro instrumento relativo a los derechos humanos. ${ }^{126}$ Destaca, entonces, la amplia jurisdicción que le permite resolver casos con base en cualquier tratado de derechos humanos, haya sido o no adoptado en el ámbito de la Unión Africana, pero siempre y cuando sea vinculante para el Estado respectivo. ${ }^{127}$ Por lo tanto, independientemente de que ello sea positivo o negativo, si esta facultad se interpreta de una forma liberal, no habrá tema o área alguna de derechos humanos que se encuentre fuera del ámbito de control de la Corte. Lo anterior corresponderá absolutamente a este tribunal establecerlo, pues el mismo Protocolo le permite determinar el ámbito de su propia jurisdicción. ${ }^{128}$

Las comunicaciones deben cumplir con ciertos requisitos de admisibilidad. El Protocolo no hace una mención precisa a ellos sino que simplemente se remite a la Carta Africana, específicamente a las condiciones

126 Artículos 3o., 5o. y 34, párrafo 6o., del Protocolo.

127 Por ejemplo, un tratado de derechos humanos adoptado por las Naciones Unidas, como el Pacto Internacional de Derechos Civiles y Políticos de 1966 que goza de una amplia aceptación por los Estados africanos. No obstante, no es claro si la Corte tiene también competencia para conocer de casos en donde se aleguen violaciones a derechos garantizados por el Protocolo a la Carta Africana de Derechos Humanos y de los Pueblos sobre los Derechos de las Mujeres en África, puesto que éste instrumento solamente contempla un mecanismo de supervisión a través de la presentación de informes estatales a la Comisión y establece que la Corte sólo tiene facultades para interpretar el tratado en todo lo relativo a su aplicación — artículos 26 y 27-. Asimismo, ya hemos señalado que la Carta Africana sobre los Derechos y el Bienestar del Niño contempla como órgano supervisor a un Comité de los Derechos y el Bienestar del Niño que tiene facultades para recibir informes estatales sobre la implementación y cumplimiento de los derechos y hacer las observaciones respectivas, y para tramitar comunicaciones - artículos 43, 44 y 45-. Este instrumento simplemente no otorga competencia alguna a la Corte.

128 Artículo 3o., párrafo 2o. 
ya señaladas para la admisión de comunicaciones ante la Comisión. ${ }^{129}$ En este sentido, corresponde a la Corte elaborar reglas más específicas para el trámite de las comunicaciones a través de la adopción de su Reglamento. ${ }^{130}$ No obstante, el Protocolo señala algunas disposiciones generales aplicables al respecto.

Si la comunicación es presentada directamente por un particular, la Corte puede solicitar la opinión de la Comisión respecto a su admisibilidad. Además, si así lo considera, puede remitir directamente la comunicación a la Comisión. ${ }^{131} \mathrm{Si}$ el caso es admisible, la Corte puede recibir promociones escritas de las partes y celebrar audiencias. Además, durante cualquier etapa del proceso puede proponer a las partes una solución amistosa de acuerdo a lo establecido por la Carta Africana. ${ }^{132}$

Por regla general, los procesos deben ser públicos, sin embargo, si existen razones que así lo justifiquen, la Corte puede celebrar audiencias in camera. Durante el proceso, las partes tienen derecho a ser representadas y, en casos donde el "interés de la justicia" así lo requiera, podrán contar con representación legal gratuita. ${ }^{133}$ Esta última posibilidad es más probable que llegue a tener lugar, tratándose de víctimas que presenten directamente su caso a la Corte. Debe resaltarse que se trata de un rasgo original del Protocolo que no está previsto para las cortes Europea e Interamericana de Derechos Humanos, particularmente tratándose de la primera, puesto que las víctimas tienen jus standi. Lo importante, por lo

129 Artículos 6o., párrafo 2o., del Protocolo y 56 de la Carta.

130 Artículo 8o. del Protocolo. La elaboración del Reglamento se encuentra a cargo de un comité de jueces, $c f r$. "Activity Report...", cit., nota 114, p. 5. Sobre la importancia del Reglamento de la Corte y los temas que debe abordar $c f r$. Udombana, Nsongurua J., The African Regional Human Rights Court: Modelling its Rules of Procedure, Copenhague, Danish Centre for Human Rights, 2002.

131 Artículo 6o., párrafos 1o. y 3o. Destaca que la Corte pueda pedirle opinión a la Comisión para el estudio de la admisibilidad. En el ámbito del sistema interamericano de derechos humanos no se encuentra prevista una disposición así, puesto que corresponde a la Comisión Interamericana de Derechos Humanos referirse a la admisibilidad del caso, ya desde la presentación de la demanda a la Corte Interamericana de Derechos Humanos. Por otro lado, el envío del caso a la Comisión Africana puede darse en el supuesto de que el Estado demandado no sea parte del Protocolo.

132 Artículo 9o. del Protocolo.

133 Artículo 10, párrafos 10. y 2o., del Protocolo. 
tanto, sería la interpretación que la Corte debe darle al "interés de la justicia" para conceder la representación legal gratuita. ${ }^{134}$

Como sucede en otros tribunales internacionales de su tipo, la Corte Africana puede ordenar a los Estados la adopción de medidas provisionales para evitar daños irreparables a las víctimas en casos de extrema gravedad y urgencia. ${ }^{135}$ Sin embargo, aunque las sentencias de la Corte son obligatorias, el Protocolo no menciona expresamente que también las decisiones relativas a las medidas provisionales tengan la misma naturaleza, por lo que su carácter vinculante no es muy obvio.

Las sentencias de la Corte deben ser dictadas dentro de los noventa días siguientes a las deliberaciones finales. Estas decisiones son definitivas, obligatorias y no están sujetas a apelación. No obstante, las sentencias pueden ser revisadas, aunque sólo a la luz de pruebas supervenientes. La Corte también puede interpretar sus sentencias, si alguna de las partes lo solicita. Cuando estime que el Estado demandado cometió violaciones a los derechos humanos, la Corte deberá ordenar reparaciones en favor de las víctimas, entre otras, el pago de una justa compensación. ${ }^{136}$ Aquí sobresalen sus amplias facultades para determinar las reparaciones, pues mientras la Corte Europea de Derechos Humanos solamente puede ordenar una justa satisfacción, y la Corte Interamericana de Derechos Humanos ha sido criticada por extralimitar sus facultades conforme a la Convención Americana sobre Derechos Humanos, ${ }^{137}$ en el ámbito africano es claro que la Corte puede ordenar no solamente el pago de indemnizaciones económicas sino cualquier otro tipo de reparación que estime pertinente según el caso.

El Protocolo establece que la Corte debe notificar las sentencias no sólo a las partes sino también a la Comisión y a todos los Estados miembros de la Unión Africana — no todos ellos son parte del Protocolo-, aunque es el Consejo Ejecutivo de esta organización el encargado de su-

134 Cfr. Africa Legal Aid, "Introducing the New African Court on Human and Peoples' Rights. Narrative Report of the Seminar", Accra, 1-2 de diciembre, African Coalition for an Effective African Court of Human and Peoples' Rights, http://www.african courtcoalition.org/content_files/files/NarrativeReportAFLA_ACHP1_2Dec06.doc, p. 5 (última visita el 17 de agosto de 2007).

135 Artículo 27, párrafo 2o., del Protocolo.

136 Artículos 27, párrafo 1o., 28 y 31, del Protocolo.

137 Cfr. el artículo 41 de la Convención Europea y el artículo 63, párrafo 1o., de la Convención Americana. 
pervisar su ejecución. ${ }^{138}$ Finalmente, en sus informes anuales de actividades presentados a la Asamblea General la Corte debe hacer mención de aquellos Estados que no hayan dado cumplimiento a las sentencias respectivas. $^{139}$

Un punto importante que debe destacarse es el relativo al eventual incumplimiento de las sentencias. Como sus homólogas Europea e Interamericana, la Corte Africana no tiene facultades para imponer sus sentencias. Es decir, su función se limita a determinar si un Estado ha violado o no los derechos garantizados por la Carta Africana y si, por lo tanto, como ha incurrido en responsabilidad internacional, debe efectuar las reparaciones que correspondan. Aunque el Consejo Ejecutivo de la Unión Africana es el órgano encargado de supervisar el cumplimiento de sus sentencias, a diferencia del Comité de Ministros del Consejo de Europa, aquél no tiene facultades para imponer sanciones a los Estados. Esta facultad corresponde a la Asamblea General de la Unión Africana, aunque su Acta Constitutiva sólo prevé esta posibilidad para situaciones donde se hayan cometido genocidios, crímenes de guerra y de lesa humanidad. ${ }^{140}$ Evidentemente, éste no es el tipo de violaciones constantes en África, por lo que la posibilidad de aplicación de sanciones se encuentra muy limitada. Las sanciones pueden ser de tipo político y económico. ${ }^{141}$ Sin embargo, lo cierto es que a casi seis años de existencia, la Asamblea General de la Unión Africana nunca ha adoptado medidas coercitivas. Por lo tanto, la sanción mínima que se puede hacer es la condena pública para presionar a los Estados a cumplir con las sentencias de la Corte. ${ }^{142}$

138 Artículo 29, párrafos 10. y 2o., del Protocolo. Este instrumento se refiere al Consejo de Ministros — ahora, Consejo Ejecutivo — de la entonces Organización de la Unidad Africana.

139 Artículo 31 del Protocolo.

140 Artículo 4o., inciso h), del Acta Constitutiva de la Unión Africana.

141 Ibidem, artículo 23, párrafo 2o.

142 Es destacable, por ejemplo, que para la elección de cinco nuevos miembros de la Comisión Africana de Derechos Humanos y de los Pueblos, la Asamblea suspendió el derecho a presentar candidatos a cinco Estados miembros por no haber cumplido con sus contribuciones, aunque no suspendió tampoco el derecho a participar en su elección. Cfr. Press Release núm. 50/2007, "The five new members of the African Commission on Human...", cit., nota 46. 


\section{Opiniones consultivas}

En su función consultiva, la Corte puede emitir opiniones a solicitud de cualquiera de los órganos de la Unión Africana, sus Estados miembros y organizaciones legalmente reconocidas por ésta, sobre cualquier disposición de la Carta Africana o cualquier otro instrumento sobre derechos humanos, siempre y cuando no verse sobre algún asunto que se encuentre en trámite ante la Comisión. ${ }^{143}$ Destaca la amplitud de la jurisdicción consultiva en términos sustantivos, pues abarca a cualquier instrumento de derechos humanos. ${ }^{144}$ Asimismo, es notable que las ONG legalmente reconocidas ante la Unión Africana puedan solicitar opiniones consultivas a diferencia del mecanismo existente en los sistemas europeo e interamericano. ${ }^{145}$ Sin embargo, existe un problema de concurrencia, pues la Comisión Africana también está facultada para emitir opiniones consultivas. ${ }^{146}$ De hecho, quizá por ello el Protocolo no señala que la Comisión pueda solicitar una opinión consultiva a la Corte, pues ella misma tiene esta facultad. ${ }^{147}$

El Protocolo no establece un procedimiento específico para la solicitud y estudio de las opiniones consultivas, sólo señala que la Corte debe fundar sus opiniones, y que los jueces tienen derecho a agregar su opinión disidente o individual. ${ }^{148}$

143 Artículo 4o. del Protocolo.

144 Inclusive, el Protocolo a la Carta Africana de Derechos Humanos y de los Pueblos sobre los Derechos de las Mujeres en África le confiere exclusivamente a la Corte la facultad para interpretar ese tratado.

145 Cfr. el artículo 64 de la Convención Americana conforme al cual solamente los Estados miembros de la Organización de Estados Americanos y algunos de sus órganos pueden solicitar opiniones consultivas a la Corte Interamericana; asimismo, el artículo 47 de la Convención Europea que señala que sólo el Comité de Ministros del Consejo de Europa puede solicitar opiniones consultivas a la Corte Europea. Cabe señalar que en el sistema europeo de derechos humanos este mecanismo nunca ha sido utilizado.

146 Artículo 45, párrafo 3o., de la Carta.

147 En el sistema interamericano, la Comisión Interamericana puede solicitar opiniones consultivas a la Corte Interamericana, pues es el único órgano facultado para emitirlas. Artículo 64, párrafo 1o., de la Convención Americana.

148 Artículo 4o., párrafo 2o., del Protocolo. 


\section{CONCLUSIONES}

El sistema africano de derechos humanos todavía se encuentra en evolución. El problema no está en los compromisos colectivos que han adquirido los Estados africanos respecto a los derechos humanos sino su actitud individual cuando se trata de demandarlos. No cabe duda que en el aspecto sustantivo la Carta Africana es un parteaguas en el derecho internacional de los derechos humanos. Sin embargo, no puede decirse lo mismo con relación a la esfera institucional y adjetiva. Las dificultades que enfrenta la Comisión, además de los de naturaleza presupuestal, se relacionan preponderantemente con la falta de fuerza vinculante de sus decisiones. Aquí, definitivamente, mucho depende de la buena voluntad de los Estados para cumplir con las obligaciones que la propia Carta Africana les impone. Precisamente por ello se pensó que un órgano de tipo judicial podría llegar a suplir muchas de las deficiencias del sistema. No obstante, consideramos que esta fe ciega en los tribunales internacionales de derechos humanos poco ayuda si no existen otras vías institucionales adecuadas que hagan que los Estados garanticen y respeten efectivamente los derechos humanos. El sistema europeo de derechos humanos y su Comité de Ministros pueden ser un buen ejemplo. Por su parte, el sistema africano se encuentra en una etapa de prueba en donde la Corte debe demostrar su capacidad para persuadir a los Estados a que cumplan con sus sentencias. Sólo así se justificarían no sólo la Corte sino los Estados africanos mismos en su afán por crear instancias nuevas antes que evitar la violación a los derechos humanos ya desde el ámbito nacional.

Por otro lado, quizá el aspecto más interesante es el estrecho vínculo existente entre los órganos de derechos humanos, reflejado principalmente en el preámbulo del Protocolo, según el cual el objetivo principal de la Corte es completar y reforzar la misión de la Comisión Africana, además de que este instrumento también dispone que para el análisis de la admisibilidad de casos, la Corte debe consultar a la Comisión y tomar en cuenta su complementariedad con ésta. Sin embargo, precisamente este es un punto que en nuestra opinión resulta problemático. Cuando se redactó la Carta Africana se estableció la creación solamente de la Comisión y no de la Corte, en este sentido, la culminación de los procedimientos, tratándose de las comunicaciones individuales e interestatales, son los informes que eventualmente prepara la Comisión y en los cuales emi- 
te sus observaciones y recomendaciones para posteriormente presentarlos a la Asamblea. Ahora bien, ni la Carta ni el Protocolo señalan el momento ni el procedimiento para que la Comisión remita casos a la Corte. Sin duda se trata de un tema que deberá ser resuelto conjuntamente por ambos órganos a través de sus Reglamentos, pues las condiciones de envío y admisión de casos deben ser establecidas de manera armónica y no unilateralmente para asegurar la eficacia del sistema.

En términos generales, la idea de establecer un órgano judicial para complementar el sistema africano de derechos humanos se propuso justamente en un momento de gran expectación en torno al proceso de democratización en África. Con ello parecen dejarse de lado los temores de los Estados africanos hacia la creación de una instancia judicial africana especializada en la materia lo cual, además, colma una laguna y conlleva un avance significativo de la protección de los derechos humanos que aminora de alguna manera las deficiencias del procedimiento ante la Comisión, al menos por lo que respecta a la carencia de fuerza vinculatoria de sus decisiones.

Sin embargo, ni en su momento la Organización de la Unidad Africana ni ahora la Unión Africana han cumplido satisfactoriamente con el financiamiento de la Comisión. En la actualidad, parece que éste seguirá siendo uno de los principales obstáculos que no solamente este órgano sino también la Corte tendrán que afrontar. La Unión Africana representa un proyecto de integración muy ambicioso en comparación con la débil economía que prevalece en ese continente. Es interesante resaltar que su Acta Constitutiva no hace mención alguna al tema, lo cual sorprende precisamente porque la falta de recursos económicos fue una de las principales razones del fracaso de la Organización de la Unidad Africana. Entonces, como el sostenimiento de la Comisión representa ya una gran carga para la Unión Africana, la Corte enfrenta el riesgo de tener que depender económicamente del apoyo externo. Lo anterior, en una situación extrema, puede llegar a comprometer su independencia. Por lo tanto, el compromiso de los Estados africanos debe pasar de la retórica a los hechos, y deben procurar que en la medida de sus limitadas posibilidades se cumpla cabalmente con el pago de cuotas y se ejerza la presión suficiente para que la Unión Africana otorgue a los órganos de derechos humanos el presupuesto necesario para su funcionamiento, en el entendido de que ni la mejor legislación ni la más elegantemente formulada puede 
por sí misma ser exitosa sin el cumplimiento debido por parte de los órganos a quienes ello les corresponde.

Por lo tanto, consideramos que no debieran tenerse demasiadas expectativas de la Corte. Sería necesario reforzar y mejorar el funcionamiento de la Comisión, pues el éxito de aquélla dependerá en gran parte de la capacidad operativa de ésta. Si los esfuerzos tendentes a consolidar el sistema africano solamente traen como resultado la burocratización de los derechos humanos derivada de la proliferación de órganos, es muy probable que siga siendo el menos desarrollado y efectivo de los sistemas regionales en la materia. 